\title{
Weak and entropy solutions for a class of nonlinear inhomogeneous Neumann boundary value problem with variable exponent
}

\author{
STANISLAS OUARO \\ Laboratoire d'Analyse Mathématique des Equations (LAME), \\ UFR. Sciences Exactes et Appliquées, Université de Ouagadougou, \\ 03 BP 7021 Ouaga 03, Ouagadougou, Burkina Faso \\ email: souaro@univ-ouaga.bf, ouaro@yahoo.fr
}

\begin{abstract}
We study the existence and uniqueness of weak and entropy solutions for the nonlinear inhomogeneous Neumann boundary value problem involving the $p(x)$-Laplace of the form $-\operatorname{div} a(x, \nabla u)+|u|^{p(x)-2} \mathfrak{u}=f$ in $\Omega, a(x, \nabla u) \cdot \eta=\varphi$ on $\partial \Omega$, where $\Omega$ is a smooth bounded open domain in $\mathbb{R}^{N}, N \geq 3, p \in C(\bar{\Omega})$ and $p(x)>1$ for $x \in \bar{\Omega}$. We prove the existence and uniqueness of a weak solution for data $\varphi \in \mathrm{L}^{\left(p_{-}\right)^{\prime}}(\partial \Omega)$ and $f \in \mathrm{L}^{\left(\mathrm{p}_{-}\right)^{\prime}}(\Omega)$, the existence and uniqueness of an entropy solution for $\mathrm{L}^{1}$-data $f$ and $\varphi$ independent of $u$ and the existence of weak solutions for $f$ dependent on $u$ and $\varphi \in \mathrm{L}^{\left(\mathrm{p}_{-}\right)^{\prime}}(\Omega)$.
\end{abstract}

\section{RESUMEN}

Estudiamos la existencia y unicidad de soluciones y entropía débil para el problema no lineal inhomogéneos de Neumann con valores de frontera que involucra el $p(x)$ - Laplace de la forma $-\operatorname{div} a(x, \nabla u)+|\mathfrak{u}|^{p(x)-2} \mathfrak{u}=f$ en Omega, $a(x, \nabla u) \cdot \eta=\varphi$ sobre $\partial \Omega$, donde Omega es en un dominio abierto suave y acotado en $\mathbb{R}^{N}, N \geq 3, p \in C(\bar{\Omega})$ y $p(x)>1$ para $x \in \bar{\Omega}$. Probamos la existencia y unicidad de una solución débil para $\varphi \in \mathrm{L}^{\left(\mathfrak{p}_{-}\right)^{\prime}}(\partial \Omega)$ and $\mathrm{f} \in \mathrm{L}^{\left(\mathfrak{p}_{-}\right)^{\prime}}(\Omega)$, la existencia y unicidad de una solución de entropía para $L^{1}$-data $f$ y $\varphi$ independiente de $u$ y la existencia de soluciones débiles para $f$ dependiente sobre $u$ y $\varphi \in \mathrm{L}^{\left(p_{-}\right)^{\prime}}(\Omega)$.

Keywords and Phrases: Generalized Lebesgue and Sobolev spaces; Weak solution; Entropy solution; $p(x)$-Laplace operator.

2010 AMS Mathematics Subject Classification: 35J20, 35J25, 35D30, 35B38, 35J60. 


\section{Introduction}

The purpose of this paper is to study the existence and uniqueness of weak and entropy solutions to the following nonlinear inhomogeneous Neumann problem involving the $p(x)$-Laplace

$$
\left\{\begin{array}{l}
-\operatorname{div} a(x, \nabla u)+|u|^{p(x)-2} u=f \text { in } \Omega \\
a(x, \nabla u) \cdot \eta=\varphi \text { on } \partial \Omega
\end{array}\right.
$$

where $\Omega \subset \mathbb{R}^{N}(N \geq 3)$ is a bounded open domain with smooth boundary and $\eta$ is the unit outward normal on $\partial \Omega$.

The study of various mathematical problems with variable exponent has recieved considerable attention in recent years (see $[4,7,8-15,17,19,24-27,29,30,33,34]$ ). These problems concern applications (see $[21,22,31,32,35])$ and raise many difficult mathematical problems.

The operator $-\operatorname{div} a(x, \nabla \mathfrak{u})$ is called $p(x)$-Laplace, which becomes $p$-Laplace when $p(x) \equiv p$ (a constant). It possesses more complicated nonlinearities than the $p$-Laplace. For related results involving the p-Laplace, see [2,3]. In [2], the authors studied the problem

$$
\left\{\begin{array}{l}
-\operatorname{div} \mathfrak{a}(x, \nabla \mathfrak{u})+\gamma(\mathfrak{u}) \ni \phi \text { in } \Omega, \\
\mathfrak{a}(x, \nabla \mathfrak{u}) \cdot \eta+\beta(\mathfrak{u}) \ni \psi \text { on } \partial \Omega,
\end{array}\right.
$$

where $\eta$ is the unit outward normal on $\partial \Omega, \psi \in \mathrm{L}^{1}(\partial \Omega)$ and $\phi \in \mathrm{L}^{1}(\Omega)$. The nonlinearities $\gamma$ and $\beta$ are maximal monotone graphs in $\mathbb{R}^{2}$ such that $0 \in \gamma(0)$ and $0 \in \beta(0)$. They proved under a range condition the existence and uniqueness of weak and entropy solutions to the problem (1.2). Following these ideas, Ouaro and Soma [24] proved the existence and uniqueness of weak and entropy solutions for a class of homogeneous nonlinear Neumann boundary value problem of the form

$$
\left\{\begin{array}{l}
-\operatorname{div} a(x, \nabla u)+|u|^{p(x)-2} \mathfrak{u}=f \text { in } \Omega \\
\frac{\partial u}{\partial v}=0 \text { on } \partial \Omega
\end{array}\right.
$$

where $\Omega \subset \mathbb{R}^{N}(N \geq 3)$ is a bounded open domain with smooth boundary and $\frac{\partial u}{\partial v}$ is the outer unit normal derivative on $\partial \Omega$.

In this paper, our aim is to prove the existence and uniqueness of weak and entropy solutions to the nonlinear Neumann boundary value problem (1.1) in order to generalize the results in [24]. The paper is presented as follows. In section 2, we introduce some fundamental preliminary results that we use in this work. The existence and the uniqueness of weak solution for (1.1) is proved in section 3 when the data $f$ and $\varphi$ belongs to $L^{\left(p_{-}\right)^{\prime}}$. In section 4 , we prove some existence results of weak solution to the problem (1.1) for an $f$ assumed to depend on $u$ and for a boundary datum $\varphi \in \mathrm{L}^{\left(\mathrm{p}_{-}\right)^{\prime}}(\partial \Omega)$. Finally, in section 5 , we prove the existence and the uniqueness of an entropy solution of (1.1) when the data $f$ and $\varphi$ belongs to $L^{1}$. 


\section{Assumptions and preliminaries}

In this work, we study the problem (1.1) for a variable exponent $p($.$) which is continuous, more$ precisely, we assume that

$$
\left\{\begin{array}{l}
\mathrm{p}(.): \bar{\Omega} \rightarrow \mathbb{R} \text { is a continuous function such that } \\
1<\mathrm{p}_{-} \leq \mathrm{p}_{+}<+\infty
\end{array}\right.
$$

where $p_{-}:=e s s \inf _{x \in \Omega} p(x)$.

We denote $p_{+}:=$ess $\sup p(x)$.

For the vector fields $a(.,$.$) , we assume that a(x, \xi): \Omega \times \mathbb{R}^{N} \rightarrow \mathbb{R}^{N}$ is Carathéodory and is the continuous derivative with respect to $\xi$ of the mapping $A: \Omega \times \mathbb{R}^{N} \rightarrow \mathbb{R}, A=A(x, \xi)$, i.e. $a(x, \xi)=\nabla_{\xi} A(x, \xi)$ such that:

- The following equality holds true

$$
A(x, 0)=0,
$$

for almost every $x \in \Omega$.

- There exists a positive constant $\mathrm{C}_{1}$ such that

$$
|\mathrm{a}(x, \xi)| \leq \mathrm{C}_{1}\left(\mathrm{j}(\mathrm{x})+|\xi|^{p(x)-1}\right)
$$

for almost every $x \in \Omega$ and for every $\xi \in \mathbb{R}^{N}$ where $j$ is a nonnegative function in $\mathrm{L}^{\mathrm{p}^{\prime}(.)}(\Omega)$, with $1 / p(x)+1 / p^{\prime}(x)=1$

- There exists a positive constant $C_{2}$ such that for almost every $x \in \Omega$ and for every $\xi, \eta \in \mathbb{R}^{N}$ with $\xi \neq \eta$,

$$
(a(x, \xi)-a(x, \eta)) \cdot(\xi-\eta)>0 .
$$

- The following inequalities hold true

$$
|\xi|^{p(x)} \leq a(x, \xi) \cdot \xi \leq p(x) A(x, \xi)
$$

for almost every $x \in \Omega$ and for every $\xi \in \mathbb{R}^{\mathrm{N}}$.

Remark 2.1. Since for almost every $x \in \Omega, a(x,$.$) is a gradient and is monotone then the$ primitive $\mathrm{A}(\mathrm{x},$.$) of \mathrm{a}(\mathrm{x},$.$) is necessarily convex.$

As the exponent $p($.$) appearing in (2.3) and (2.5) depends on the variable x$, we must work with Lebesgue and Sobolev spaces with variable exponents. 
We define the Lebesgue space with variable exponent $L^{p(.)}(\Omega)$ as the set of all measurable function $u: \Omega \rightarrow \mathbb{R}$ for which the convex modular

$$
\rho_{\mathfrak{p}(.)}(\mathfrak{u}):=\int_{\Omega}|\mathfrak{u}|^{\mathfrak{p}(x)} \mathrm{d} x
$$

is finite. If the exponent is bounded, i.e., if $p_{+}<\infty$, then the expression

$$
|u|_{p(.)}:=\inf \left\{\lambda>0: \rho_{p(.)}(u / \lambda) \leq 1\right\}
$$

defines a norm in $L^{p(.)}(\Omega)$, called the Luxembourg norm. The space $\left(L^{p(.)}(\Omega),|\cdot|_{p(.)}\right)$ is a separable Banach space. Moreover, if $1<p_{-} \leq p_{+}<+\infty$, then $\mathrm{L}^{p(\cdot)}(\Omega)$ is uniformly convex, hence reflexive, and its dual space is isomorphic to $\mathrm{L}^{\mathrm{p}^{\prime}(.)}(\Omega)$, where $\frac{1}{\mathrm{p}(x)}+\frac{1}{\mathrm{p}^{\prime}(x)}=1$. Finally, we have the Hölder type inequality:

$$
\left|\int_{\Omega} u v d x\right| \leq\left(\frac{1}{p_{-}}+\frac{1}{p_{-}^{\prime}}\right)|u|_{p_{(.)}}|v|_{p^{\prime}(.)},
$$

for all $u \in \mathrm{L}^{\mathrm{p}(\cdot)}(\Omega)$ and $v \in \mathrm{L}^{\mathrm{p}^{\prime}(\cdot)}(\Omega)$.

Now, let

$$
\mathrm{W}^{1, p(.)}(\Omega):=\left\{u \in \mathrm{L}^{\mathrm{p}(.)}(\Omega):|\nabla u| \in \mathrm{L}^{\mathrm{p}(.)}(\Omega)\right\}
$$

which is a Banach space equipped with the following norm

$$
\|\mathfrak{u}\|_{1, \mathfrak{p}(.)}:=|\mathfrak{u}|_{\mathfrak{p}(.)}+|\nabla \mathfrak{u}|_{\mathfrak{p}(.)} .
$$

The space $\left(W^{1, p(.)}(\Omega),\|u\|_{1, p(.)}\right)$ is a separable and reflexive Banach space; more details can be found in [17].

An important role in manipulating the generalized Lebesgue and Sobolev spaces is played by the modular $\rho_{\mathfrak{p}(.)}$ of the space $\mathrm{L}^{\mathrm{p}(.)}(\Omega)$. We have the following result (cf. [15]):

Lemma 2.2. If $\mathrm{u}_{\mathrm{n}}, \mathrm{u} \in \mathrm{L}^{\mathrm{p}(.)}(\Omega)$ and $\mathrm{p}_{+}<+\infty$, then the following properties hold:

$$
\begin{aligned}
& |u|_{p(.)}>1 \Rightarrow|u|_{p_{(.)}}^{p_{-}} \leq \rho_{\mathfrak{p}(.)}(u) \leq|u|_{p_{(.)}}^{p_{+}} ;
\end{aligned}
$$

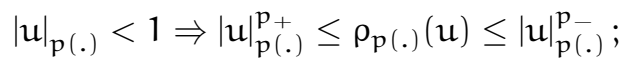

$$
\begin{aligned}
& \left.\left.|\mathfrak{u}|_{\mathfrak{p}(.)}<1 \text { (respectively }=1 ;>1\right) \Leftrightarrow \rho_{\mathfrak{p}(.)}(\mathfrak{u})<1 \text { (respectively }=1 ;>1\right) \text {; } \\
& \left.\left.\left|u_{n}\right|_{p(.)} \rightarrow 0 \text { (respectively } \rightarrow+\infty\right) \Leftrightarrow \rho_{p}(.)\left(u_{n}\right) \rightarrow 0 \text { (respectively } \rightarrow+\infty\right) \text {; } \\
& \rho_{\mathfrak{p}(.)}\left(u /|u|_{p(.)}\right)=1 \text {. }
\end{aligned}
$$

For a measurable function $u: \Omega \longrightarrow \mathbb{R}$, we introduce the following notation:

$$
\rho_{1, \mathfrak{p}(.)}(u):=\int_{\Omega}|u|^{p(x)} \mathrm{d} x+\int_{\Omega}|\nabla u|^{p(x)} \mathrm{d} x .
$$

We have the following lemma (cf. [33]):

Lemma 2.3. If $u \in W^{1, p(.)}(\Omega)$, then the following properties hold true:

$$
\begin{aligned}
& \left.\|\mathfrak{u}\|_{1, \mathfrak{p}(.)}<1 \text { (respectively }=1 ;>1\right) \Leftrightarrow \rho_{1, \mathfrak{p}(.)}(\mathfrak{u})<1(\text { respectively }=1 ;>1) \\
& \|\mathfrak{u}\|_{1, \mathfrak{p}(.)}<1 \Leftrightarrow\|\mathfrak{u}\|_{1, \mathfrak{p}(.)}^{p_{+}} \leq \rho_{1, \mathfrak{p}(.)}(\mathfrak{u}) \leq\|\mathfrak{u}\|_{1, \mathfrak{p}(.)}^{p_{-}} \\
& \|u\|_{1, \mathfrak{p}(.)}>1 \Leftrightarrow\|\mathfrak{u}\|_{1, \mathfrak{p}(.)}^{p_{-}} \leq \rho_{1, \mathfrak{p}(.)}(\mathfrak{u}) \leq\|u\|_{1, \mathfrak{p}(.)}^{p_{+}} .
\end{aligned}
$$


Put

$$
p^{\partial}(x):=(p(x))^{\partial}:=\left\{\begin{array}{l}
\frac{(N-1) p(x)}{N-p(x)}, \text { if } p(x)<N \\
\infty, \text { if } p(x) \geq N .
\end{array}\right.
$$

We have the following useful result (cf. $[13,34])$.

Proposition 2.4. Let $\mathrm{p} \in \mathrm{C}(\bar{\Omega})$ and $\mathrm{p}_{-}>1$. If $\mathrm{q} \in \mathrm{C}(\partial \Omega)$ satisfies the condition

$$
1 \leq \mathrm{q}(x)<\mathrm{p}^{\partial}(x), \forall x \in \partial \Omega,
$$

then, there is a compact embedding $\mathrm{W}^{1, \mathrm{p}(\mathrm{x})}(\Omega) \hookrightarrow \mathrm{L}^{\mathrm{q}(\mathrm{x})}(\partial \Omega)$. In particular, there is a compact embedding $\mathrm{W}^{1, \mathfrak{p}(\mathrm{x})}(\Omega) \hookrightarrow \mathrm{L}^{\mathrm{p}(\mathrm{x})}(\partial \Omega)$.

Let us introduce the following notation: given two bounded measurable functions $p(),. q():. \Omega \rightarrow \mathbb{R}$, we write

$$
q(.) \ll p(.) \text { if ess } \inf _{x \in \Omega}(p(x)-q(x))>0 .
$$

\section{Weak solution}

In this section, we study the existence and uniqueness of a weak solution of (1.1) where the data $\varphi \in \mathrm{L}^{\left(\mathfrak{p}_{-}\right)^{\prime}}(\partial \Omega)$ and $f \in \mathrm{L}^{\left(\mathrm{p}_{-}\right)^{\prime}}(\Omega)$. The definition of weak solution is the following:

Definition 3.1. A weak solution of (1.1) is a measurable function $\mathfrak{u}: \Omega \longrightarrow \mathbb{R}$ such that

$$
u \in W^{1, p(\cdot)}(\Omega),
$$

and

$$
\int_{\Omega} \mathrm{a}(x, \nabla \mathfrak{u}) . \nabla v \mathrm{~d} x+\int_{\Omega}|\mathfrak{u}|^{p(x)-2} \mathfrak{u} v \mathrm{~d} x-\int_{\partial \Omega} \varphi v d \sigma=\int_{\Omega} f v d x, \quad \forall v \in W^{1, p(.)}(\Omega),
$$

where $\mathrm{d} \sigma$ is the surface measure on $\partial \Omega$.

Let $E$ denote the generalized Sobolev space $W^{1, p(.)}(\Omega)$.

If we denote the functional $J: E \rightarrow \mathbb{R}$ by

$$
J(\mathfrak{u})=\int_{\Omega} A(x, \nabla u) d x+\int_{\Omega} \frac{1}{p(x)}|\mathfrak{u}|^{p(x)} d x-\int_{\partial \Omega} \varphi u d \sigma-\int_{\Omega} f u d x
$$

then

$$
\left\langle J^{\prime}(u), v\right\rangle=\int_{\Omega} \mathrm{a}(x, \nabla u) . \nabla v d x+\int_{\Omega}|\mathfrak{u}|^{p(x)-2} u v d x-\int_{\partial \Omega} \varphi v d \sigma-\int_{\Omega} f v d x, \quad \text { for all } u, v \in E .
$$

Therefore, the weak solution of (1.1) corresponds to the critical point of the functional J.

The main result of this section is the following:

Theorem 3.2. Assume that (2.1)-(2.5) hold. Then there exists a unique weak solution of (1.1).

Proof. * Existence. With the techniques that became standard by now, it is not difficult to 
verify that $J$ is well-defined on $E$, is of class $C^{1}(E, \mathbb{R})$ and is weakly lower semi-continuous (see for example $[6,19,24,25,26,28])$. To end the proof of the existence part, we just have to prove that $\mathrm{J}$ is bounded from below and coercive.

Using (2.5) and since $E$ is continuously embedded in $L^{p-}(\Omega)$, we have

$$
\begin{aligned}
& J(u)=\int_{\Omega} A(x, \nabla u) d x+\int_{\Omega} \frac{1}{p(x)}|\mathfrak{u}|^{p(x)} d x-\int_{\partial \Omega} \varphi u d \sigma-\int_{\Omega} f u d x \\
& \geq \int_{\Omega} \frac{1}{\mathfrak{p}(x)}|\nabla \mathfrak{u}|^{p(x)} \mathrm{d} x+\int_{\Omega} \frac{1}{\mathfrak{p}(x)}|\mathfrak{u}|^{p(x)} \mathrm{d} x-\|\varphi\|_{\left(\mathfrak{p}_{-}\right)^{\prime}, \partial \Omega}\|\mathfrak{u}\|_{\mathfrak{p}_{-}, \partial \Omega}-\|\mathfrak{f}\|_{\left(\mathfrak{p}_{-}\right)^{\prime}, \Omega}\|\mathfrak{u}\|_{\mathfrak{p}_{-}, \Omega} \\
& \geq \frac{1}{p^{+}} \rho_{1, p(.)}(u)-c\|\varphi\|_{\left(p_{-}\right)^{\prime}, \partial \Omega}\|u\|_{1, p(.)}-C\|\mathfrak{u}\|_{1, p(.)},
\end{aligned}
$$

where $\|\mathfrak{u}\|_{\mathfrak{p}_{-}, \Omega}=\left(\int_{\Omega}|\mathfrak{u}|^{\mathfrak{p}_{-}} \mathrm{d} x\right)^{\frac{1}{p_{-}}}$and $\|\mathfrak{u}\|_{p_{-}, \partial \Omega}=\left(\int_{\partial \Omega}|\mathfrak{u}|^{\mathfrak{p}_{-}} \mathrm{d} \sigma\right)^{\frac{1}{p_{-}}}$.

As $\varphi \in \mathrm{L}^{\left(\mathbf{p}_{-}\right)^{\prime}}(\partial \Omega)$, then $\|\varphi\|_{\left(\mathbf{p}_{-}\right)^{\prime}, \partial \Omega}<+\infty$. Also, for the coercivity of $\mathrm{J}$, we will work with $u$ such that $\|u\|_{1, \mathfrak{p}(.)}>1$. Then, by Lemma 2.3 we obtain that

$$
J(u) \geq \frac{1}{p^{+}}\|u\|_{1, p(.)}^{p_{-}}-C_{3}\|u\|_{1, p(.)}
$$

As $p_{-}>1$, then $J$ is coercive.

If $\|\mathfrak{u}\|_{1, p(.)}<1$, we have that

$$
\begin{aligned}
J(u) & \geq \frac{1}{p^{+}}\|\mathfrak{u}\|_{1, \mathfrak{p}(.)}^{p_{+}}-C_{3}\|u\|_{1, p(.)} \\
& \geq-C_{3}>-\infty
\end{aligned}
$$

Therefore, J is bounded from below.

Since the functional $\mathrm{J}$ is proper, lower semi-continuous and coercive, then it has a minimizer which is a weak solution of (1.1).

* Uniqueness. Let $u_{1}$ and $\mathfrak{u}_{2}$ be two weak solutions of (1.1).

With $\mathfrak{u}_{1}$ as weak solution, we take $v=\mathfrak{u}_{1}-\mathfrak{u}_{2}$ in (3.1) to get

$$
\int_{\Omega} a\left(x, \nabla u_{1}\right) \cdot \nabla\left(u_{1}-u_{2}\right) d x+\int_{\Omega}\left|u_{1}\right|^{p(x)-2} u_{1}\left(u_{1}-u_{2}\right) d x-\int_{\partial \Omega} \varphi\left(u_{1}-u_{2}\right) d \sigma=\int_{\Omega} f(x)\left(u_{1}-u_{2}\right) d x .
$$

Similarly, with $\mathfrak{u}_{2}$ as weak solution, we take $\varphi=\mathfrak{u}_{2}-\mathfrak{u}_{1}$ to obtain

$$
\int_{\Omega} a\left(x, \nabla u_{2}\right) \cdot \nabla\left(u_{2}-u_{1}\right) d x+\int_{\Omega}\left|u_{2}\right|^{p(x)-2} u_{2}\left(u_{2}-u_{1}\right) d x-\int_{\partial \Omega} \varphi\left(u_{2}-u_{1}\right) d \sigma=\int_{\Omega} f(x)\left(u_{2}-u_{1}\right) d x .
$$

After adding (3.2) and (3.3), we obtain

$$
\int_{\Omega}\left(a\left(x, \nabla u_{1}\right)-a\left(x, \nabla u_{2}\right)\right) \cdot\left(\nabla u_{1}-\nabla u_{2}\right)+\int_{\Omega}\left(\left|u_{1}\right|^{p(x)} u_{1}-\left|u_{2}\right|^{p(x)} u_{2}\right)\left(u_{1}-u_{2}\right) d x=0
$$


Using (2.4), we deduce from (3.4) that

$$
\int_{\Omega}\left(\left|u_{1}(x)\right|^{p(x)} u_{1}(x)-\left|u_{2}(x)\right|^{p(x)} u_{2}(x)\right)\left(u_{1}(x)-u_{2}(x)\right) d x=0 .
$$

Since $p_{-}>1$, the following relation is true for any $\xi, \eta \in \mathbb{R}, \xi \neq \eta$ (cf. [14])

$$
\left(|\xi|^{p(x)-2} \xi-|\eta|^{p(x)-2} \eta\right)(\xi-\eta)>0 .
$$

Therefore, from (3.5), we get

$$
\left(\left|u_{1}(x)\right|^{p(x)} u_{1}(x)-\left|u_{2}(x)\right|^{p(x)} u_{2}(x)\right)\left(u_{1}(x)-u_{2}(x)\right)=0 \text {, a.e. } x \in \Omega .
$$

Now, we use (3.6) to get

$$
u_{1}(x)=u_{2}(x) \text { a.e. } x \in \Omega \text {. }
$$

and uniqueness is true

\section{Weak solutions for a right-hand side dependent on $u$}

In this section, we show the existence result of weak solution to some general problem. More precisely, we prove that there exists at least one weak solution to the problem

$$
\begin{cases}-\operatorname{div} a(x, \nabla u)+|u|^{p(x)-2} \mathfrak{u}=f(x, \mathfrak{u}) & \text { in } \Omega, \\ \mathfrak{a}(x, \nabla \mathfrak{u}) \cdot \eta=\varphi & \text { on } \partial \Omega\end{cases}
$$

where $\varphi \in \mathrm{L}^{\left(\mathrm{p}_{-}\right)^{\prime}}(\partial \Omega)$.

We study (4.1) under the assumptions (2.1)-(2.5) and the following additional assumptions on $f$.

$f(x, t): \Omega \times \mathbb{R} \longrightarrow \mathbb{R}$ is Carathéodory and there exists two positive constants $C_{4}, C_{5}$ such that

$$
|f(x, t)| \leq C_{4}+C_{5}|t|^{\beta(x)-1},
$$

for every $t \in \mathbb{R}$ and for almost every $x \in \Omega$ with $0 \leq \beta(.) \ll p($.$) .$

Let

$$
F(x, t)=\int_{0}^{t} f(x, s) d s .
$$

As mentioned before, we look for distributional solution of (4.1) in the following sense:

Definition 4.1. A weak solution of (4.1) is a measurable function $\mathfrak{u}: \Omega \longrightarrow \mathbb{R}$ such that $\mathfrak{u} \in$ $\mathrm{W}^{1, \mathrm{p}(.)}(\Omega)$ and for all $v \in \mathrm{W}^{1, \mathrm{p}(.)}(\Omega)$

$$
\int_{\Omega} \mathrm{a}(x, \nabla \mathfrak{u}) . \nabla v \mathrm{~d} x+\int_{\Omega}|\mathfrak{u}|^{p(x)-2} u v d x-\int_{\partial \Omega} \varphi v d \sigma=\int_{\Omega} f(x, u) v d x .
$$


We have the following existence result:

Theorem 4.2. Assume that (2.1)-(2.5) and (4.2) hold. Then, the problem (4.1) admits at least one weak solution.

Proof. Let $g(u)=\int_{\Omega} F(x, u) d x, \quad$ for all $u \in E$. The functional $g$ is of class $C^{1}(E, \mathbb{R})$ with the derivative given by $\left\langle\mathrm{g}^{\prime}(\mathrm{u}), v\right\rangle=\int_{\Omega} \mathrm{f}(\mathrm{x}, \mathrm{u}) v \mathrm{~d} x, \quad \forall \mathrm{u}, v \in \mathrm{E}$.

Consequently,

$$
J(u)=\int_{\Omega} A(x, \nabla u) d x+\int_{\Omega} \frac{1}{p(x)}|u|^{p(x)} d x-\int_{\partial \Omega} \varphi u d \sigma-\int_{\Omega} F(x, u) d x, u \in E
$$

is such that $J$ is of class $C^{1}(E, \mathbb{R})$ and is lower semi-continuous.

We then have to prove that $\mathrm{J}$ is bounded from below and coercive in order to complete the proof. From (4.2), we have $|\mathrm{F}(\mathrm{x}, \mathrm{t})| \leq \mathrm{C}\left(1+|\mathrm{t}|^{\beta(x)}\right)$ and then

$$
J(u) \geq \frac{1}{p_{+}} \int_{\Omega}|\nabla u|^{p(x)} \mathrm{d} x+\frac{1}{p_{+}} \int_{\Omega}|u|^{p(x)} \mathrm{d} x-\int_{\partial \Omega} \varphi u d \sigma-C \int_{\Omega}|u|^{\beta(x)} \mathrm{d} x-\operatorname{Cmeas}(\Omega) .
$$

Let $M>1$ be a fixed real number (to be chosen later) and $\epsilon:=$ ess $\inf _{x \in \Omega}(p(x)-\beta(x))$. We have

$$
\begin{aligned}
& \geq \frac{1}{2 p_{+}} \rho_{1, \mathfrak{p}(.)}(u)+\int_{\{|\mathfrak{u}| \leq M\}}\left(\frac{1}{2 p_{+}}|\mathfrak{u}|^{p(x)}-C|u|^{\beta(x)}\right) d x+ \\
& \int_{\{|u|>M\}}\left(\frac{1}{2 p_{+}}|u|^{p(x)}-C|u|^{\beta(x)}\right) d x-\operatorname{Cmeas}(\Omega)-C^{\prime \prime}\|u\|_{1, p(.)} \\
& \geq \frac{1}{2 p_{+}} \rho_{1, p(.)}(u)+\int_{\{|u|>M\}}\left(\frac{1}{2 p_{+}}|u|^{p(x)}-C|u|^{\beta(x)}\right) d x-C^{\prime \prime}\|u\|_{1, p(.)}-\left(M^{\beta+}+1\right) \operatorname{Cmeas}(\Omega) \\
& \left.\geq \frac{1}{2 p_{+}} \rho_{1, p(.)}(u)+\int_{\{|u|>M\}}|u|^{\beta(x)}\left(\frac{1}{2 p_{+}}|u|^{p(x)-\beta(x)}-C\right)\right) d x-C^{\prime \prime}\|u\|_{1, p(.)}-\left(M^{\beta+}+1\right) C \operatorname{meas}(\Omega) \\
& \geq \frac{1}{2 p_{+}} \rho_{1, p(.)}(u)+\left(\frac{1}{2 p_{+}} M^{\epsilon}-C\right) \int_{\{|u|>M\}}|u|^{\beta(x)} d x-C^{\prime \prime}\|u\|_{1, p(.)}-\left(M^{\beta+}+1\right) \operatorname{Cmeas}(\Omega) \\
& \geq \frac{1}{p_{+}}\|u\|_{1, p(.)}^{p_{-}}-C^{\prime \prime}\|u\|_{1, p(.)}-\left(M^{\beta+}+1\right) \operatorname{Cmeas}(\Omega),
\end{aligned}
$$

For all $M>\max \left(\left(2 p_{+} C\right)^{\frac{1}{e}}, 1\right)$ and all $u \in E$ with $\|u\|_{1, p(.)}>1$.

Since $1<p_{-}$it follows that $\mathrm{J}(\mathrm{u}) \longrightarrow+\infty$ as $\|\mathrm{u}\|_{\mathrm{E}} \longrightarrow+\infty$.

Consequently, $\mathrm{J}$ is bounded from below and coercive. The proof is then complete.

Assume now that $F^{+}(x, t)=\int_{0}^{t} f^{+}(x, s) d s$ is such that there exists $C_{6}>0, C_{7}>0$ such that

$$
\left|f^{+}(x, t)\right| \leq C_{6}+C_{7}|t|^{\beta(x)-1},
$$

where $0 \leq \beta(.) \ll p($.$) .$

Then we have the following result: 
Theorem 4.3 Under assumptions (2.1)-(2.5) and (4.4), the problem (4.1) admits at least one weak solution.

Proof. As $f=f^{+}-f^{-}$, let $F^{-}(x, t)=\int_{0}^{t} f^{-}(x, s) d s$.

Then

$$
\begin{aligned}
J(u) & =\int_{\Omega} A(x, \nabla u) d x+\int_{\Omega} \frac{1}{p(x)}|u|^{p(x)} d x+\int_{\Omega} F^{-}(x, u) d x-\int_{\Omega} F^{+}(x, u) d x-\int_{\partial \Omega} \varphi u d \sigma \\
& \geq \int_{\Omega} A(x, \nabla u) d x+\int_{\Omega} \frac{1}{p(x)}|u|^{p(x)} d x-\int_{\Omega} F^{+}(x, u) d x-\int_{\partial \Omega} \varphi v d \sigma .
\end{aligned}
$$

Therefore, similarly as in the proof of Theorem 4.2, the result of Theorem 4.3 follows immediately.

\section{$5 \quad$ Entropy solutions}

In this section, we study the existence of entropy solution for the problem (1.1) when the data $\mathrm{f} \in \mathrm{L}^{1}(\Omega)$ and $\varphi \in \mathrm{L}^{1}(\partial \Omega)$.

We first recall some notations.

For any $k>0$, we define the truncation function $T_{k}$ by $T_{k}(s):=\max \{-k, \min \{k, s\}\}$.

Let $\Omega$ be a bounded open subset of $\mathbb{R}^{N}$ of class $C^{1}$ and $1 \leq p()<.+\infty$. It is well known( see [20] or [23]) that if $u \in W^{1, p(.)}(\Omega)$, it is possible to define the trace of $u$ on $\partial \Omega$. More precisely, there is a bounded operator $\tau$ from $W^{1, p(.)}(\Omega)$ into $L^{p(\cdot)}(\partial \Omega)$ such that $\tau(u)=\left.u\right|_{\partial \Omega}$ whenever $u \in C(\bar{\Omega})$.

Set

$$
\mathcal{T}^{1, \mathfrak{p}(.)}(\Omega)=\left\{\mathfrak{u}: \Omega \longrightarrow \mathbb{R} \text {, measurable such that } \mathrm{T}_{\mathrm{k}}(\mathrm{u}) \in \mathrm{W}^{1, \mathfrak{p}(.)}(\Omega) \text {, for any } \mathrm{k}>0\right\} .
$$

In [1], the authors have proved the following

Proposition 5.1 Let $u \in \mathcal{T}^{1, p(.)}(\Omega)$. Then there exists a unique measurable function $v: \Omega \longrightarrow \mathbb{R}^{N}$ such that $\nabla \mathrm{T}_{\mathrm{k}}(\mathrm{u})=v \chi_{\{|\mathbf{u}|<\mathrm{k}\}}$, for all $\mathrm{k}>0$. The function $\boldsymbol{v}$ is denoted by $\nabla \mathrm{u}$. Moreover if $u \in W^{1, p(.)}(\Omega)$ then $v \in\left(\mathrm{L}^{\mathrm{p}(.)}(\Omega)\right)^{\mathrm{N}}$ and $v=\nabla u$ in the usual sense.

It is easy to see that, in general, it is not possible to define the trace of an element of $\mathcal{T}^{1, p(.)}(\Omega)$. In demension one it is enough to consider the function $u(x)=\frac{1}{x}$ for $\left.x \in\right] 0,1[$. Therefore, we are going to define following [2,3], the trace for the elements of a subset $\mathcal{T}_{\mathrm{tr}}^{1, \mathfrak{p}(.)}(\Omega)$ of $\mathcal{T}^{1, p(.)}(\Omega)$. $\mathcal{T}_{\operatorname{tr}}^{1, p(.)}(\Omega)$ will be the set of functions $u \in \mathcal{T}^{1, p(.)}(\Omega)$ such that there exists a sequence $\left(u_{n}\right)_{n} \subset$ $W^{1, p(.)}(\Omega)$ satisfying the following conditions:

$\left(C_{1}\right) u_{n} \rightarrow u$ a.e in $\Omega$.

$\left(\mathrm{C}_{2}\right) \nabla \mathrm{T}_{\mathrm{k}}\left(\mathrm{u}_{\mathrm{n}}\right) \rightarrow \nabla \mathrm{T}_{\mathrm{k}}(\mathrm{u})$ in $\mathrm{L}^{1}(\Omega)$ for any $\mathrm{k}>0$.

$\left(C_{3}\right)$ There exists a measurable function $v$ on $\partial \Omega$, such that $u_{n} \rightarrow v$ a.e in $\partial \Omega$.

The function $v$ is the trace of $u$ in the generalized sense introduced in $[2,3]$. In the sequel the trace of $u \in \mathcal{T}_{\mathrm{tr}}^{1, \mathfrak{p}(.)}(\Omega)$ on $\partial \Omega$ will be denoted by $\operatorname{tr}(u)$. If $u \in W^{1, p(.)}(\Omega), \operatorname{tr}(u)$ coincides with $\tau(u)$ in 
the usual sense. Moreover, for $u \in \mathcal{T}_{\operatorname{tr}}^{1, p(.)}(\Omega)$ and for every $k>0, \tau\left(T_{k}(u)\right)=T_{k}(\operatorname{tr}(u))$ and if $\varphi \in \mathbb{W}^{1, p(.)}(\Omega) \cap \mathrm{L}^{\infty}(\Omega)$ then $(u-\varphi) \in \mathcal{T}_{\operatorname{tr}}^{1, p(.)}(\Omega)$ and $\operatorname{tr}(u-\varphi)=\operatorname{tr}(u)-\operatorname{tr}(\varphi)$.

We can now introduce the notion of entropy solution of (1.1).

Definition 5.2. A measurable function $u$ is an entropy solution to problem (1.1) if $\mathfrak{u} \in \mathcal{T}_{\mathrm{tr}}^{1, \mathfrak{p}(.)}(\Omega)$, $|u|^{p(x)-2} u \in L^{1}(\Omega)$ and for every $k>0$,

$$
\int_{\Omega} a(x, \nabla u) \cdot \nabla T_{k}(u-v) d x+\int_{\Omega}|u|^{p(x)-2} u T_{k}(u-v) d x \leq \int_{\partial \Omega} \varphi T_{k}(u-v) d \sigma+\int_{\Omega} f(x) T_{k}(u-v) d x
$$

for all $v \in W^{1, p(.)}(\Omega) \cap \mathrm{L}^{\infty}(\Omega)$.

Our main result in this section is the following:

Theorem 5.3. Assume (2.1)-(2.5), $\mathrm{f} \in \mathrm{L}^{1}(\Omega)$ and $\varphi \in \mathrm{L}^{1}(\partial \Omega)$. Then, there exists a unique entropy solution $\mathrm{u}$ to problem (1.1).

The following propositions are useful for the proof of Theorem 5.3.

Proposition 5.4. Assume (2.1)-(2.5), $\mathrm{f} \in \mathrm{L}^{1}(\Omega)$ and $\varphi \in \mathrm{L}^{1}(\partial \Omega)$. Let $\mathrm{u}$ be an entropy solution of (1.1). If there exists a positive constant $M$ such that

$$
\int_{\{|u|>k\}} k^{q(x)} d x \leq M
$$

then

$$
\int_{\left\{|\nabla u|^{\alpha(.)}>\mathrm{k}\right\}} \mathrm{k}^{\mathrm{q}(\mathrm{x})} \mathrm{d} x \leq\|\mathrm{f}\|_{\mathrm{L}^{1}(\Omega)}+\|\varphi\|_{\mathrm{L}^{1}(\partial \Omega)}+\mathrm{M}, \text { for all } \mathrm{k}>0,
$$

where $\alpha()=.p() /.(q()+1$.$) .$

Proof. Taking $v=0$ in the entropy inequality (5.1) and using (2.5), we get

$$
\int_{\Omega}\left|\nabla \mathrm{T}_{\mathrm{k}}(\mathrm{u})\right|^{\mathrm{p}(\mathrm{x})} \mathrm{d} x \leq \mathrm{k}\left(\|\mathrm{f}\|_{\mathrm{L}^{1}(\Omega)}+\|\varphi\|_{\mathrm{L}^{1}(\partial \Omega)}\right) \text { for all } \mathrm{k}>0 .
$$

Therefore, defining $\psi:=\frac{1}{k} T_{k}(u)$, we have for all $k>0$,

$$
\int_{\Omega} k^{p(x)-1}|\nabla \psi|^{p(x)} \mathrm{d} x=\frac{1}{k} \int_{\Omega}\left|\nabla \mathrm{T}_{k}(u)\right|^{p(x)} \mathrm{d} x \leq\|f\|_{\mathrm{L}^{1}(\Omega)}+\|\varphi\|_{\mathrm{L}^{1}(\partial \Omega)} .
$$

From the above inequality, from the definition of $\alpha($.$) and (5.2), we get$

$$
\begin{aligned}
\int_{\left\{|\nabla u|^{\alpha(.)}>k\right\}} k^{q(x)} d x & \leq \int_{\left\{|\nabla u|^{\alpha(.)}>k\right\} \cap\{|u| \leq k\}} k^{q(x)} d x+\int_{\{|u|>k\}} k^{q(x)} d x \\
& \leq \int_{\{|u| \leq k\}} k^{q(x)}\left(\frac{|\nabla u|^{\alpha(x)}}{k}\right)^{\frac{p(x)}{\alpha(x)}} \mathrm{d} x+M \\
& \leq\|f\|_{L^{1}(\Omega)}+\|\varphi\|_{L^{1}(\partial \Omega)}+M, \text { for all } k>0 .
\end{aligned}
$$

Proposition 5.5. Assume (2.1)-(2.5), $\mathrm{f} \in \mathrm{L}^{1}(\Omega)$ and $\varphi \in \mathrm{L}^{1}(\partial \Omega)$. Let $\mathrm{u}$ be an entropy solution of (1.1), then

$$
\int_{\Omega}\left|\nabla \mathrm{T}_{\mathrm{k}}(\mathrm{u})\right|^{\mathrm{p}(\mathrm{x})} \mathrm{dx} \leq \mathrm{k}\left(\|\mathrm{f}\|_{\mathrm{L}^{1}(\Omega)}+\|\varphi\|_{\mathrm{L}^{1}(\partial \Omega)}\right) \text { for all } \mathrm{k}>0
$$


and

$$
\left\||u|^{p(x)-2} u\right\|_{1}=\left\||u|^{p(x)-1}\right\|_{1} \leq\|f\|_{L^{1}(\Omega)}+\|\varphi\|_{L^{1}(\partial \Omega)} .
$$

Proof. The inequality (5.3) is already obtained in the proof of Proposition 5.2. Let's prove (5.4). Taking $\varphi=0$ in (5.1), we get for all $k>0$,

$$
\int_{\Omega}|\mathfrak{u}|^{p(x)-2} u T_{k}(u) d x \leq k\left(\|f\|_{L^{1}(\Omega)}+\|\varphi\|_{L^{1}(\partial \Omega)}\right),
$$

then

$$
\int_{\{|\boldsymbol{u}|>k\}}|u|^{p(x)-2} u T_{k}(u) d x \leq k\left(\|f\|_{L^{1}(\Omega)}+\|\varphi\|_{L^{1}(\partial \Omega)}\right) .
$$

From the inequality above, we obtain

$$
k \int_{\{u>k\}}|u|^{p(x)-2} u d x-k \int_{\{u<-k\}}|u|^{p(x)-2} u d x \leq k\left(\|f\|_{L^{1}(\Omega)}+\|\varphi\|_{L^{1}(\partial \Omega)}\right),
$$

which imply

$$
\int_{\{\mathfrak{u}>\boldsymbol{k}\}}|\mathfrak{u}|^{p(x)-2} \mathfrak{u d x}-\int_{\{\mathfrak{u}<-k\}}|\mathfrak{u}|^{\mathfrak{p}(x)-2} u d x \leq\|f\|_{L^{1}(\Omega)}+\|\varphi\|_{L^{1}(\partial \Omega)} .
$$

The last inequality means

$$
\int_{\{|\mathfrak{u}|>k\}}|\mathfrak{u}|^{p(x)-1} \mathrm{~d} x \leq\|f\|_{L^{1}(\Omega)}+\|\varphi\|_{L^{1}(\partial \Omega)} \text { for all } k>0 .
$$

We use Fatou's Lemma in (5.5) by letting $k$ goes to 0 to obtain (5.4).

Proposition 5.6. Assume that (2.1)-(2.5) hold, $\mathrm{f} \in \mathrm{L}^{1}(\Omega)$ and $\varphi \in \mathrm{L}^{1}(\partial \Omega)$. Let $\mathrm{u}$ be an entropy solution of (1.1), then

$$
\int_{\{|\mathfrak{u}| \leq k\}}\left|\nabla \mathrm{T}_{\mathrm{k}}(\mathrm{u})\right|^{\mathrm{p}_{-}} \mathrm{dx} \leq \mathrm{C}(\mathrm{k}+1) \text { for all } \mathrm{k}>0 .
$$

Proof. Note that

$$
\begin{aligned}
& \int_{\{|\mathfrak{u}| \leq k\}}\left|\nabla \mathrm{T}_{\mathrm{k}}(\mathrm{u})\right|^{\mathbf{p}_{-}} \mathrm{dx}=\int_{\{|\mathfrak{u}| \leq k,|\nabla \mathfrak{u}|>1\}}\left|\nabla \mathrm{T}_{\mathrm{k}}(\mathrm{u})\right|^{\mathbf{p}_{-}} \mathrm{d} x+\int_{\{|\mathfrak{u}| \leq k,|\nabla u| \leq 1\}}\left|\nabla \mathrm{T}_{\mathrm{k}}(\mathrm{u})\right|^{\mathbf{p}_{-}} \mathrm{dx} \\
& \leq \int_{\{|\mathfrak{u}| \leq k,|\nabla u|>1\}}\left|\nabla \mathrm{T}_{\mathrm{k}}(\mathrm{u})\right|^{\mathbf{p}_{-} \mathrm{d} x+\operatorname{meas}(\Omega)} \\
& \leq \int_{\{|u| \leq k\}}\left|\nabla \mathrm{T}_{k}(\mathrm{u})\right|^{\mathfrak{p}(x)} \mathrm{d} x+\operatorname{meas}(\Omega) .
\end{aligned}
$$

Since $\int_{\{|\mathfrak{u}| \leq k\}}\left|\nabla \mathrm{T}_{k}(\mathfrak{u})\right|^{p(x)} \mathrm{d} x \leq \mathrm{k}\left(\|\mathbf{f}\|_{\mathrm{L}^{1}(\Omega)}+\|\varphi\|_{\mathrm{L}^{1}(\partial \Omega)}\right)$, we obtain

$$
\int_{\{|u| \leq k\}}\left|\nabla \mathrm{T}_{\mathrm{k}}(\mathrm{u})\right|^{\mathrm{p}_{-}} \mathrm{dx} \leq \mathrm{k}\left(\|\mathrm{f}\|_{\mathrm{L}^{1}(\Omega)}+\|\varphi\|_{\mathrm{L}^{1}(\partial \Omega)}\right)+\operatorname{meas}(\Omega) \text { for all } \mathrm{k}>0 .
$$


Proposition 5.7. Assume that (2.1)-(2.5) hold, $\mathrm{f} \in \mathrm{L}^{1}(\Omega)$ and $\varphi \in \mathrm{L}^{1}(\partial \Omega)$. Let $\mathrm{u}$ be an entropy solution of (1.1). Then

$$
\operatorname{meas}\{|\mathbf{u}|>\mathrm{h}\} \leq \frac{\|\mathrm{f}\|_{\mathrm{L}^{1}(\Omega)}+\|\varphi\|_{\mathrm{L}^{1}(\partial \Omega)}}{\mathrm{h}^{p_{-}-1}} \text { for all } \mathrm{h} \geq 1,
$$

and

$$
\operatorname{meas}\{|\nabla \mathrm{u}|>\mathrm{h}\} \leq \frac{\|\mathrm{f}\|_{\mathrm{L}^{1}(\Omega)}+\|\varphi\|_{\mathrm{L}^{1}(\partial \Omega)}}{\mathrm{h}^{\mathrm{p}_{-}-1}} \text { for all } \mathrm{h} \geq 1 \text {. }
$$

Proof.

$$
\begin{aligned}
& \int_{\Omega}|\mathfrak{u}|^{\mathfrak{p}(x)-1} \mathrm{~d} x=\int_{\{|\mathfrak{u}| \leq \boldsymbol{h}\}}|\mathfrak{u}|^{p(x)-1} \mathrm{~d} x+\int_{\{|\mathfrak{u}|>\boldsymbol{h}\}}|\mathfrak{u}|^{p(x)-1} \mathrm{~d} x \\
& \geq \int_{\{|u|>h\}}|u|^{p(x)-1} \mathrm{~d} x \\
& \geq \int_{\{|u|>h\}} h^{p(x)-1} d x \\
& \geq h^{p_{--1}} \text { meas }\{|u|>h\} \text { since } h \geq 1 \text {. }
\end{aligned}
$$

Then, by (5.4) we deduce (5.7).

We next prove (5.8).

For $k, \lambda \geq 0$, set

$$
\Phi(k, \lambda)=\operatorname{meas}\left\{|\nabla u|^{p_{-}}>\lambda,|u|>k\right\}
$$

We have

$$
\Phi(k, 0) \leq \operatorname{meas}\{|u|>k\}
$$

For $k \geq 1$, we obtain by (5.7)

$$
\Phi(k, 0) \leq\left(\|f\|_{L^{1}(\Omega)}+\|\varphi\|_{L^{1}(\partial \Omega)}\right) k^{1-p_{-}} .
$$

Using the fact that the function $\lambda \longmapsto \Phi(k, \lambda)$ is nonincreasing, we get for $k>0$ and $\lambda>0$, that

$$
\begin{aligned}
\Phi(0, \lambda) & =\frac{1}{\lambda} \int_{0}^{\lambda} \Phi(0, \lambda) \mathrm{d} s \leq \frac{1}{\lambda} \int_{0}^{\lambda} \Phi(0, s) \mathrm{d} s \\
& \leq \frac{1}{\lambda} \int_{0}^{\lambda}[\Phi(0, s)+(\Phi(k, 0)-\Phi(k, s))] \mathrm{d} s \\
& \leq \Phi(k, 0)+\frac{1}{\lambda} \int_{0}^{\lambda}(\Phi(0, s)-\Phi(k, s)) \mathrm{ds} .
\end{aligned}
$$

Now, let us observe that

$$
\Phi(0, s)-\Phi(k, s)=\operatorname{meas}\left\{|u| \leq k,|\nabla u|^{p_{-}}>s\right\} .
$$

Then, thanks to (5.6), we get

$$
\int_{0}^{+\infty}(\Phi(0, s)-\Phi(k, s)) d s=\int_{\{|u| \leq k\}}|\nabla u|^{p_{-}} \mathrm{d} x \leq \mathrm{C}(\mathrm{k}+1)
$$


where $C=\max \left(\operatorname{meas}(\Omega),\|f\|_{\mathrm{L}^{1}(\Omega)}+\|\varphi\|_{\mathrm{L}^{1}(\partial \Omega)}\right)$.

It follows that

$$
\Phi(0, \lambda) \leq \frac{C(k+1)}{\lambda}+\left(\|f\|_{L^{1}(\Omega)}+\|\varphi\|_{L^{1}(\partial \Omega)}\right) k^{1-p_{-}}, \text {for all } k \geq 1, \lambda>0 .
$$

In particular, we have

$$
\Phi(0, \lambda) \leq \frac{\mathrm{C}(\mathrm{k}+1)}{\lambda}+\left(\|f\|_{\mathrm{L}^{1}(\Omega)}+\|\varphi\|_{\mathrm{L}^{1}(\partial \Omega)}\right) k^{1-p_{-}}, \text {for all } k \geq 1, \lambda \geq 1
$$

We now set

$$
f_{\lambda}(k)=\frac{C(k+1)}{\lambda}+\left(\|f\|_{L^{1}(\Omega)}+\|\varphi\|_{L^{1}(\partial \Omega)}\right) k^{1-p_{-}}, \text {for all } k \geq 1,
$$

where $\lambda \geq 1$ is a fixed real number.

The minimization of $f_{\lambda}$ in $k$ gives

$$
\Phi(0, \lambda) \leq\left(\|f\|_{L^{1}(\Omega)}+\|\varphi\|_{L^{1}(\partial \Omega)}\right) \lambda^{-\left(1 /\left(p_{-}\right)^{\prime}\right)},
$$

for all $\lambda \geq 1$.

Setting $\lambda=h^{p-}$ in (5.9) gives (5.8).

Proof of Theorem 5.3. * Uniqueness of entropy solution. Let $h>0$ and $\mathfrak{u}_{1}, \mathfrak{u}_{2}$ be two entropy solutions of (1.1). We write the entropy inequality (5.1) corresponding to the solution $u_{1}$, with $T_{h}\left(u_{2}\right)$ as a test function, and to the solution $u_{2}$, with $T_{h}\left(u_{1}\right)$ as a test function. Upon addition, we get

$$
\left\{\begin{array}{l}
\int_{\left\{\left|u_{1}-T_{h}\left(u_{2}\right)\right| \leq k\right\}} a\left(x, \nabla u_{1}\right) \cdot \nabla\left(u_{1}-T_{h}\left(u_{2}\right)\right) d x+\int_{\left\{\left|u_{2}-T_{h}\left(u_{1}\right)\right| \leq k\right\}} a\left(x, \nabla u_{2}\right) \cdot \nabla\left(u_{2}-T_{h}\left(u_{1}\right)\right) d x \\
+\int_{\Omega}\left|u_{1}\right|^{p(x)-2} u_{1} T_{k}\left(u_{1}-T_{h}\left(u_{2}\right)\right) d x+\int_{\Omega}\left|u_{2}\right|^{p(x)-2} u_{2} T_{k}\left(u_{2}-T_{h}\left(u_{1}\right)\right) d x \leq \\
\int_{\partial \Omega} \varphi\left(T_{k}\left(u_{1}-T_{h}\left(u_{2}\right)\right)+T_{k}\left(u_{2}-T_{h}\left(u_{1}\right)\right)\right) d \sigma+\int_{\Omega} f\left(T_{k}\left(u_{1}-T_{h}\left(u_{2}\right)\right)+T_{k}\left(u_{2}-T_{h}\left(u_{1}\right)\right)\right) d x .
\end{array}\right.
$$

Define now

$$
E_{1}:=\left\{\left|u_{1}-u_{2}\right| \leq k,\left|u_{2}\right| \leq h\right\}, \quad E_{2}:=E_{1} \cap\left\{\left|u_{1}\right| \leq h\right\}, \quad \text { and } E_{3}:=E_{1} \cap\left\{\left|u_{1}\right|>h\right\} .
$$

We start with the first integral in (5.10). By (2.5), we have 


$$
\left\{\begin{array}{c}
\int_{\left\{\left|u_{1}-T_{h}\left(u_{2}\right)\right| \leq k\right\}} a\left(x, \nabla u_{1}\right) \cdot \nabla\left(u_{1}-T_{h}\left(u_{2}\right)\right) d x \\
=\int_{\left\{\left|u_{1}-T_{h}\left(u_{2}\right)\right| \leq k\right\} \cap\left\{\left|u_{2}\right| \leq h\right\}} a\left(x, \nabla u_{1}\right) \cdot \nabla\left(u_{1}-T_{h}\left(u_{2}\right)\right) d x \\
\quad+\int_{\left\{\left|u_{1}-T_{h}\left(u_{2}\right)\right| \leq k\right\} \cap\left\{\left|u_{2}\right|>h\right\}} a\left(x, \nabla u_{1}\right) \cdot \nabla\left(u_{1}-T_{h}\left(u_{2}\right)\right) d x \\
=\int_{\left\{\left|u_{1}-T_{h}\left(u_{2}\right)\right| \leq k\right\} \cap\left\{\left|u_{2}\right| \leq h\right\}} a\left(x, \nabla u_{1}\right) \cdot \nabla\left(u_{1}-u_{2}\right) d x+\int_{\left\{\left|u_{1}-h \operatorname{sign}\left(u_{2}\right)\right| \leq k\right\} \cap\left\{\left|u_{2}\right|>h\right\}} a(x) \\
\geq \int_{\left\{\left|u_{1}-T_{h}\left(u_{2}\right)\right| \leq k\right\} \cap\left\{\left|u_{2}\right| \leq h\right\}} a\left(x, \nabla u_{1}\right) \cdot \nabla\left(u_{1}-u_{2}\right) d x=\int_{E_{1}} a\left(x, \nabla u_{1}\right) \cdot \nabla\left(u_{1}-u_{2}\right) d x \\
=\int_{E_{2}} a\left(x, \nabla u_{1}\right) \cdot \nabla\left(u_{1}-u_{2}\right) d x+\int_{E_{3}} a\left(x, \nabla u_{1}\right) \cdot \nabla\left(u_{1}-u_{2}\right) d x \\
=\int_{E_{2}} a\left(x, \nabla u_{1}\right) \cdot \nabla\left(u_{1}-u_{2}\right) d x+\int_{E_{3}} a\left(x, \nabla u_{1}\right) \cdot \nabla u_{1} d x-\int_{E_{3}} a\left(x, \nabla u_{1}\right) \cdot \nabla u_{2} d x \\
\geq \int_{E_{2}} a\left(x, \nabla u_{1}\right) \cdot \nabla\left(u_{1}-u_{2}\right) d x-\int_{E_{3}} a\left(x, \nabla u_{1}\right) \cdot \nabla u_{2} d x .
\end{array}\right.
$$

Using (2.3) and (2.6), we estimate the last integral in (5.11) as follows:

where $\left.\left.|| \nabla u_{1}\right|^{p(x)-1}\right|_{p^{\prime}(.),\left\{h<\left|u_{1}\right| \leq h+k\right\}}=\left\|\left|\nabla u_{1}\right|^{p(x)-1}\right\|_{L^{p^{\prime}(.)}\left(\left\{h<\left|u_{1}\right| \leq h+k\right\}\right)}$.

The quantity $C_{1}\left(|j|_{p^{\prime}(.)}+\left.\left.|| \nabla u_{1}\right|^{p(x)-1}\right|_{p^{\prime}(.),\left\{h<\left|u_{1}\right| \leq h+k\right\}}\right)$ can be written as follows

$$
C_{1}\left(|j|_{p^{\prime}(.)}+\left.\left.|| \nabla T_{h+k}\left(u_{1}\right)\right|^{p(x)-1}\right|_{p^{\prime}(.),\left\{h<\left|u_{1}\right| \leq h+k\right\}}\right)<+\infty
$$

since $T_{h+k}\left(u_{1}\right) \in W^{1, p(.)}(\Omega)$ and $j \in L^{p^{\prime}(.)}(\Omega)$.

We deduce by Proposition 5.7 that

$C_{1}\left(|j|_{p^{\prime}(.)}+\left.\left.|| \nabla u_{1}\right|^{p(x)-1}\right|_{p^{\prime}(.),\left\{h<\left|u_{1}\right| \leq h+k\right\}}\right)\left|\nabla u_{2}\right|_{p(.),\left\{h-k<\left|u_{1}\right| \leq h\right\}}$ converges to 0 as $h \rightarrow+\infty$.

Therefore, from (5.11) and (5.12), we obtain

$$
\int_{\left\{\left|u_{1}-T_{h}\left(u_{2}\right)\right| \leq k\right\}} a\left(x, \nabla u_{1}\right) \cdot \nabla\left(u_{1}-T_{h}\left(u_{2}\right)\right) d x \geq I_{h}+\int_{E_{2}} a\left(x, \nabla u_{1}\right) \cdot \nabla\left(u_{1}-u_{2}\right) d x
$$

where $I_{h}$ converges to zero as $h \rightarrow+\infty$.

We may adopt the same procedure to treat the second term in (5.10) to obtain

$$
\int_{\left\{\left|u_{2}-T_{h}\left(u_{1}\right)\right| \leq k\right\}} a\left(x, \nabla u_{2}\right) \cdot \nabla\left(u_{2}-T_{h}\left(u_{1}\right)\right) d x \geq J_{h}-\int_{E_{2}} a\left(x, \nabla u_{2}\right) \cdot \nabla\left(u_{1}-u_{2}\right) d x
$$


where $J_{h}$ converges to zero as $h \rightarrow+\infty$.

Now set for all $h, k>0$

$$
K_{h}=\int_{\Omega}\left|u_{1}\right|^{p(x)-2} u_{1} T_{k}\left(u_{1}-T_{h}\left(u_{2}\right)\right) d x+\int_{\Omega}\left|u_{2}\right|^{p(x)-2} u_{2} T_{k}\left(u_{2}-T_{h}\left(u_{1}\right)\right) d x .
$$

We have

$$
\left|u_{1}\right|^{p(x)-2} u_{1} T_{k}\left(u_{1}-T_{h}\left(u_{2}\right)\right) \longrightarrow\left|u_{1}\right|^{p(x)-2} u_{1} T_{k}\left(u_{1}-u_{2}\right) \text { a.e in } \Omega \text { as } h \rightarrow+\infty \text {, }
$$

and

$$
\left.\left.|| u_{1}\right|^{p(x)-2} u_{1} T_{k}\left(u_{1}-T_{h}\left(u_{2}\right)\right)|\leq k| u_{1}\right|^{p(x)-1} \in L^{1}(\Omega) .
$$

Then by Lebesgue Theorem, we deduce that

$$
\lim _{h \rightarrow+\infty} \int_{\Omega}\left|u_{1}\right|^{p(x)-2} u_{1} T_{k}\left(u_{1}-T_{h}\left(u_{2}\right)\right) d x=\int_{\Omega}\left|u_{1}\right|^{p(x)-2} u_{1} T_{k}\left(u_{1}-u_{2}\right) d x .
$$

Similarly, we have

$$
\lim _{h \rightarrow+\infty} \int_{\Omega}\left|u_{2}\right|^{p(x)-2} u_{2} T_{k}\left(u_{2}-T_{h}\left(u_{1}\right)\right) d x=\int_{\Omega}\left|u_{2}\right|^{p(x)-2} u_{2} T_{k}\left(u_{2}-u_{1}\right) d x .
$$

Using (5.15) and (5.16), we get

$$
\lim _{h \rightarrow+\infty} K_{h}=\int_{\Omega}\left(\left|u_{1}\right|^{p(x)-2} u_{1}-\left|u_{2}\right|^{p(x)-2} u_{2}\right) T_{k}\left(u_{1}-u_{2}\right) d x .
$$

We next examine the right-hand side of (5.10).

For all $k>0$,

$f\left(T_{k}\left(u_{1}-T_{h}\left(u_{2}\right)\right)+T_{k}\left(u_{2}-T_{h}\left(u_{1}\right)\right)\right) \longrightarrow f\left(T_{k}\left(u_{1}-u_{2}\right)+T_{k}\left(u_{2}-u_{1}\right)\right)=0$ a.e in $\Omega$ as $h \rightarrow+\infty$,

$\varphi\left(\mathrm{T}_{k}\left(\mathrm{u}_{1}-\mathrm{T}_{\mathrm{h}}\left(\mathrm{u}_{2}\right)\right)+\mathrm{T}_{k}\left(\mathrm{u}_{2}-\mathrm{T}_{\mathrm{h}}\left(\mathrm{u}_{1}\right)\right)\right) \longrightarrow \varphi\left(\mathrm{T}_{k}\left(\mathrm{u}_{1}-\mathrm{u}_{2}\right)+\mathrm{T}_{k}\left(\mathrm{u}_{2}-\mathrm{u}_{1}\right)\right)=0$ a.e in $\partial \Omega$ as $\mathrm{h} \rightarrow+\infty$, and

$$
\begin{aligned}
& \left|f(x)\left(T_{k}\left(u_{1}-T_{h}\left(u_{2}\right)\right)+T_{k}\left(u_{2}-T_{h}\left(u_{1}\right)\right)\right)\right| \leq 2 k|f| \in L^{1}(\Omega), \\
& \left|\varphi\left(T_{k}\left(u_{1}-T_{h}\left(u_{2}\right)\right)+T_{k}\left(u_{2}-T_{h}\left(u_{1}\right)\right)\right)\right| \leq 2 k|\varphi| \in L^{1}(\partial \Omega) .
\end{aligned}
$$

Lebesgue Theorem allows us to write

$$
\lim _{h \rightarrow+\infty}\left[\int_{\partial \Omega} \varphi\left(T_{k}\left(u_{1}-T_{h}\left(u_{2}\right)\right)+T_{k}\left(u_{2}-T_{h}\left(u_{1}\right)\right)\right) d \sigma+\int_{\Omega} f\left(T_{k}\left(u_{1}-T_{h}\left(u_{2}\right)\right)+T_{k}\left(u_{2}-T_{h}\left(u_{1}\right)\right)\right) d x\right]=0 .
$$

Using (5.13), (5.14), (5.17) and (5.18), we get

$$
\left\{\begin{array}{l}
\int_{\left\{\left|\mathfrak{u}_{1}-\mathfrak{u}_{2}\right| \leq k\right\}}\left(a\left(x, \nabla u_{1}\right)-a\left(x, \nabla u_{2}\right)\right) \cdot\left(\nabla u_{1}-\nabla u_{2}\right) d x \\
+\int_{\Omega}\left(\left|u_{1}\right|^{p(x)-2} u_{1}-\left|u_{2}\right|^{p(x)-2} u_{2}\right) T_{k}\left(u_{1}-u_{2}\right) d x \leq 0 .
\end{array}\right.
$$


Therefore

$$
\int_{\Omega}\left(\left|u_{1}\right|^{p(x)-2} u_{1}-\left|u_{2}\right|^{p(x)-2} u_{2}\right) T_{k}\left(u_{1}-u_{2}\right) d x=0 .
$$

For $x$ fixed in $\Omega, s \longmapsto|s|^{p(x)-2} s$ is nondecreasing and vanishes at 0 . Then,

$$
\left(\left|u_{1}\right|^{p(x)-2} u_{1}-\left|u_{2}\right|^{p(x)-2} u_{2}\right) T_{k}\left(u_{1}-u_{2}\right) \geq 0, \forall x \in \Omega \text { and } \forall k>0 .
$$

Now, using inequality above and (5.20), for all $k \in \mathbb{R}^{+}$there exist $\Omega_{k} \subset \Omega$ with meas $\left(\Omega_{k}\right)=0$ such that for all $x \in \Omega \backslash \Omega_{k}$,

$$
\left(\left|u_{1}(x)\right|^{p(x)-2} u_{1}(x)-\left|u_{2}(x)\right|^{p(x)-2} u_{2}(x)\right) T_{k}\left(u_{1}(x)-u_{2}(x)\right)=0 .
$$

Therefore,

$$
\left(\left|\mathfrak{u}_{1}(x)\right|^{p(x)-2} \mathfrak{u}_{1}(x)-\left|\mathfrak{u}_{2}(x)\right|^{p(x)-2} \mathfrak{u}_{2}(x)\right)\left(\mathfrak{u}_{1}(x)-\mathfrak{u}_{2}(x)\right)=0, \text { for all } x \in \Omega \backslash \bigcup_{k \in \mathbb{N}^{*}} \Omega_{k} .
$$

Now, using (5.21) and (3.6), we get

$$
\mathfrak{u}_{1}=\mathfrak{u}_{2} \text { a.e. in } \Omega \text {. }
$$

* Existence of entropy solution. Let $f_{n}=T_{n}(f)$ and $\varphi_{n}=T_{n}(\varphi)$; then $\left(f_{n}\right)_{n}$ and $\left(\varphi_{n}\right)_{n}$ are in $L^{\left(p_{-}\right)^{\prime}}(\Omega)$ and $L^{\left(p_{-}\right)^{\prime}}(\partial \Omega)$ respectively and are strongly converging to $f$ in $L^{1}(\Omega)$ and to $\varphi$ in $\mathrm{L}^{1}(\partial \Omega)$ respectively. Moreover $\left\|f_{n}\right\|_{L^{1}(\Omega)} \leq \| f_{L^{1}(\Omega)}$ and $\left\|\varphi_{n}\right\|_{L^{1}(\partial \Omega)} \leq\|\varphi\|_{L^{1}(\partial \Omega)}$, for all $n \in$ $\mathbb{N}$.

Next, we consider the problem

$$
\left\{\begin{array}{l}
-\operatorname{div} a\left(x, \nabla u_{n}\right)+\left|u_{n}\right|^{p(x)-2} u_{n}=f_{n} \text { in } \Omega, \\
a\left(x, \nabla u_{n}\right) \cdot \eta=\varphi_{n} \text { on } \partial \Omega .
\end{array}\right.
$$

It follows from Theorem 3.2 that there exists a unique $u_{n} \in W^{1, p(.)}(\Omega)$ such that

$$
\int_{\Omega} \mathrm{a}\left(x, \nabla \mathrm{u}_{\mathrm{n}}\right) \cdot \nabla v \mathrm{~d} x+\int_{\Omega}\left|\mathrm{u}_{\mathrm{n}}\right|^{p(x)-2} u_{n} v \mathrm{~d} x=\int_{\partial \Omega} \varphi_{n} v d \sigma+\int_{\Omega} f_{n} v d x
$$

for all $v \in W^{1, p(.)}(\Omega)$.

Our aim is to prove that these approximated solutions $u_{n}$ tend, as $n$ goes to infinity, to a measurable function $u$ which is an entropy solution to the limit problem (1.1). To start with, we prove the following lemma:

Lemma 5.8. For any $\mathrm{k}>0,\left\|\mathrm{~T}_{\mathrm{k}}\left(\mathrm{u}_{\mathrm{n}}\right)\right\|_{1, \mathrm{p}(.)} \leq 1+\mathrm{C}$ where $\mathrm{C}=\mathrm{C}\left(\mathrm{k}, \varphi, \mathrm{f}, \mathrm{p}_{-}, \mathrm{p}_{+}\right.$, meas $\left.(\Omega)\right)$ is a positive constant.

Proof. By taking $v=T_{k}\left(u_{n}\right)$ in (5.23), we get

$$
\int_{\Omega} a\left(x, \nabla u_{n}\right) \cdot \nabla T_{k}\left(u_{n}\right)+\int_{\Omega}\left|u_{n}\right|^{p(x)-2} u_{n} T_{k}\left(u_{n}\right) d x=\int_{\partial \Omega} \varphi_{n} T_{k}\left(u_{n}\right) d \sigma+\int_{\Omega} f_{n} T_{k}\left(u_{n}\right) d x .
$$


Since all the terms in the left-hand side of equality above are nonnegative and

$$
\int_{\partial \Omega} \varphi_{n} T_{k}\left(u_{n}\right) d \sigma+\int_{\Omega} f_{n} T_{k}\left(u_{n}\right) d x \leq k\left(\left\|\varphi_{n}\right\|_{L^{1}(\partial \Omega)}+\left\|f_{n}\right\|_{L^{1}(\Omega)}\right) \leq k\left(\|\varphi\|_{L^{1}(\partial \Omega)}+\|f\|_{L^{1}(\Omega)}\right) ;
$$

by using (2.5) we obtain

$$
\int_{\Omega}\left|\nabla \mathrm{T}_{k}\left(\mathrm{u}_{n}\right)\right|^{p(x)} \mathrm{d} x \leq k\left(\|\varphi\|_{\mathrm{L}^{1}(\partial \Omega)}+\|f\|_{\mathrm{L}^{1}(\Omega)}\right)
$$

and

$$
\int_{\Omega}\left|u_{n}\right|^{p(x)-2} u_{n} T_{k}\left(u_{n}\right) d x \leq k\left(\|\varphi\|_{L^{1}(\partial \Omega)}+\|f\|_{L^{1}(\Omega)}\right) .
$$

The inequality (5.25) is equivalent to

$$
\int_{\left\{\left|u_{n}\right| \leq k\right\}}\left|T_{k}\left(u_{n}\right)\right|^{p(x)} d x+\int_{\left\{\left|u_{n}\right|>k\right\}}\left|u_{n}\right|^{p(x)-2} u_{n} T_{k}\left(u_{n}\right) d x \leq k\left(\|\varphi\|_{L^{1}(\partial \Omega)}+\|f\|_{L^{1}(\Omega)}\right) .
$$

Therefore,

$$
\int_{\left\{\left|u_{n}\right| \leq k\right\}}\left|T_{k}\left(u_{n}\right)\right|^{p(x)} d x \leq k\left(\|\varphi\|_{L^{1}(\partial \Omega)}+\|f\|_{L^{1}(\Omega)}\right) .
$$

Furthermore

$$
\begin{aligned}
\int_{\left\{\left|u_{n}\right|>k\right\}}\left|T_{k}\left(u_{n}\right)\right|^{p(x)} d x & =\int_{\left\{\left|u_{n}\right|>k\right\}} k^{p(x)} d x \\
& \leq\left\{\begin{array}{l}
k^{p^{+}} \operatorname{meas}(\Omega) \text { if } k \geq 1, \\
\operatorname{meas}(\Omega) \text { if } k<1 .
\end{array}\right.
\end{aligned}
$$

This allows us to write

$$
\int_{\left\{\left|u_{n}\right|>k\right\}}\left|T_{k}\left(u_{n}\right)\right|^{p(x)} d x \leq\left(1+k^{p+}\right) \operatorname{meas}(\Omega) .
$$

Relations (5.26) and (5.27) give

$$
\int_{\Omega}\left|\mathrm{T}_{k}\left(u_{n}\right)\right|^{p(x)} \mathrm{d} x \leq k\left(\|\varphi\|_{L^{1}(\partial \Omega)}+\|f\|_{L^{1}(\Omega)}\right)+\left(1+k^{p^{+}}\right) \operatorname{meas}(\Omega) .
$$

Hence, adding (5.24) and (5.28), it yields

$$
\rho_{1, p(.)}\left(T_{k}\left(u_{n}\right)\right) \leq 2 k\left(\|\varphi\|_{L^{1}(\partial \Omega)}+\|f\|_{L^{1}(\Omega)}\right)+\left(1+k^{p_{+}}\right) \operatorname{meas}(\Omega)=C\left(k, \varphi, f, p_{+}, \operatorname{meas}(\Omega)\right) .
$$

If $\left\|T_{k}\left(u_{n}\right)\right\|_{1, p(.)} \geq 1$, we have

$$
\left\|T_{k}\left(u_{n}\right)\right\|_{1, p(.)}^{p_{-}} \leq \rho_{1, p(.)}\left(T_{k}\left(u_{n}\right)\right) \leq C\left(k, \varphi, f, p_{+}, \operatorname{meas}(\Omega)\right),
$$

which is equivalent to

$$
\left\|T_{k}\left(u_{n}\right)\right\|_{1, p(.)} \leq\left(C\left(k, \varphi, f, p_{+}, \operatorname{meas}(\Omega)\right)\right)^{\frac{1}{p_{-}}}=C\left(k, \varphi, f, p_{-}, p_{+}, \operatorname{meas}(\Omega)\right) .
$$


The above inequality gives

$$
\left\|T_{k}\left(u_{n}\right)\right\|_{1, p(.)} \leq 1+C\left(k, \varphi, f, p_{-}, p_{+}, \operatorname{meas}(\Omega)\right) .
$$

Then, the proof of Lemma 5.8. is complete.

From Lemma 5.8. we deduce that for any $k>0$, the sequence $\left(T_{k}\left(u_{n}\right)\right)$ is uniformly bounded in $W^{1, p(.)}(\Omega)$ and so in $W^{1, p}-(\Omega)$. Then, up to a subsequence we can assume that for any $k>0$, $T_{k}\left(u_{n}\right)$ converges weakly to $\sigma_{k}$ in $W^{1, p_{-}}(\Omega)$, and so $T_{k}\left(u_{n}\right)$ converges strongly to $\sigma_{k}$ in $L^{p_{-}}(\Omega)$. We next prove the following proposition:

Proposition 5.9. Assume that (2.1)-(2.5) hold and $\mathrm{u}_{\mathrm{n}} \in \mathrm{W}^{1, p(.)}(\Omega)$ is the weak solution of (5.22). Then the sequence $\left(u_{n}\right)_{n}$ is Cauchy in measure. In particular, there exists a measurable function $\mathfrak{u}$ and a subsequence still denoted $\left(\mathfrak{u}_{n}\right)_{n}$ such that $\mathfrak{u}_{\mathfrak{n}} \longrightarrow \mathfrak{u}$ in measure.

Proof. Let $s>0$ and define

$$
E_{1}:=\left\{\left|u_{n}\right|>k\right\}, \quad E_{2}:=\left\{\left|u_{m}\right|>k\right\} \quad \text { and } \quad E_{3}:=\left\{\left|T_{k}\left(u_{n}\right)-T_{k}\left(u_{m}\right)\right|>s\right\}
$$

where $k>0$ is to be fixed. We note that

$$
\left\{\left|u_{n}-u_{m}\right|>s\right\} \subset E_{1} \cup E_{2} \cup E_{3},
$$

and hence

$$
\operatorname{meas}\left\{\left|u_{n}-u_{m}\right|>s\right\} \leq \operatorname{meas}\left(E_{1}\right)+\operatorname{meas}\left(E_{2}\right)+\operatorname{meas}\left(E_{3}\right) .
$$

Let $\epsilon>0$. Using Proposition 5.7, we choose $k=k(\epsilon)$ such that

$$
\text { meas }\left(E_{1}\right) \leq \epsilon / 3 \text { and meas }\left(E_{2}\right) \leq \epsilon / 3 \text {. }
$$

Since $T_{k}\left(u_{n}\right)$ converges strongly in $L^{p}-(\Omega)$, then it is a Cauchy sequence in $L^{p_{-}}(\Omega)$.

Thus

$$
\operatorname{meas}\left(E_{3}\right) \leq \frac{1}{s^{p_{-}}} \int_{\Omega}\left|T_{k}\left(u_{n}\right)-T_{k}\left(u_{m}\right)\right|^{p_{-}} d x \leq \frac{\epsilon}{3},
$$

for all $n, m \geq n_{0}(s, \epsilon)$.

Finally, from (5.30), (5.31) and (5.32), we obtain

$$
\operatorname{meas}\left\{\left|u_{n}-u_{m}\right|>s\right\} \leq \epsilon \text { for all } n, m \geq n_{0}(s, \epsilon) .
$$

Relations (5.33) mean that the sequence $\left(u_{n}\right)_{n}$ is Cauchy sequence in measure and the proof of Proposition 5.9. is complete.

Note that as $\mathfrak{u}_{\mathfrak{n}} \longrightarrow \mathfrak{u}$ in measure, up to a subsequence, we can assume that $\mathfrak{u}_{\mathfrak{n}} \longrightarrow \mathfrak{u}$ a.e. in $\Omega$. In the sequel, we need the following two technical lemmas.

Lemma 5.10. ( cf.[30, Lemma 5.4] ) Let $\left(v_{\mathfrak{n}}\right)_{\mathfrak{n}}$ be a sequence of measurable functions in $\Omega$. If $v_{n}$ converges in measure to $v$ and is uniformly bounded in $\mathrm{L}^{\mathrm{p}(.)}(\Omega)$ for some $1 \ll \mathrm{p}(.) \in \mathrm{L}^{\infty}(\Omega)$, then $v_{\mathrm{n}} \longrightarrow v$ strongly in $\mathrm{L}^{1}(\Omega)$. 
The second technical lemma is a well known result in measure theory (cf. [16] ).

Lemma 5.11. Let $(\mathrm{X}, \mathcal{M}, \mu)$ be a measure space such that $\mu(\mathrm{X})<+\infty$. Consider a measurable function $\gamma: \mathrm{X} \longrightarrow[0,+\infty]$ such that

$$
\mu(\{x \in X: \gamma(x)=0\})=0 .
$$

Then, for every $€>0$, there exists $\delta>0$, such that

$$
\mu(\mathrm{A})<\epsilon, \text { for all } \mathrm{A} \in \mathcal{M} \text { with } \int_{\mathrm{A}} \gamma \mathrm{d} \mu<\delta .
$$

We now set to prove that the function $u$ in the Proposition 5.9 is an entropy solution of (1.1). Let $v \in W^{1, p(.)}(\Omega) \cap L^{\infty}(\Omega)$. For any $k>0$, choose $T_{k}\left(u_{n}-v\right)$ as a test function in (5.23). We get

$$
\begin{aligned}
\int_{\Omega} a\left(x, \nabla u_{n}\right) \cdot \nabla T_{k}\left(u_{n}-v\right) d x & +\int_{\Omega}\left|u_{n}\right|^{p(x)-2} u_{n} T_{k}\left(u_{n}-v\right) d x= \\
& \int_{\partial \Omega} \varphi_{n}(x) T_{k}\left(u_{n}-v\right) d \sigma+\int_{\Omega} f_{n}(x) T_{k}\left(u_{n}-v\right) d x
\end{aligned}
$$

We have the following proposition:

Proposition 5.12. Assume that (2.1)-(2.5) hold and $\mathrm{u}_{\mathrm{n}} \in \mathrm{W}^{1, p(.)}(\Omega)$ be the weak solution of (5.22). Then

(i) $\nabla \mathrm{u}_{\mathrm{n}}$ converges in measure to the weak gradient of $\mathrm{u}$;

(ii) For all $\mathrm{k}>0, \nabla \mathrm{T}_{\mathrm{k}}\left(\mathrm{u}_{\mathrm{n}}\right)$ converges to $\nabla \mathrm{T}_{\mathrm{k}}(\mathrm{u})$ in $\left(\mathrm{L}^{1}(\Omega)\right)^{\mathrm{N}}$.

(iii) For all $\mathrm{t}>0, \mathrm{a}\left(\mathrm{x}, \nabla \mathrm{T}_{\mathrm{t}}\left(\mathrm{u}_{\mathrm{n}}\right)\right)$ converges to $\mathrm{a}\left(\mathrm{x}, \nabla \mathrm{T}_{\mathrm{t}}(\mathrm{u})\right)$ in $\left(\mathrm{L}^{1}(\Omega)\right)^{\mathrm{N}}$ strongly and in $\left(\mathrm{L}^{\mathrm{p}^{\prime}(.)}(\Omega)\right)^{\mathrm{N}}$ weakly.

(iv) $u_{n}$ converges to some function $v$ a.e. on $\partial \Omega$.

Proof.

(i) We claim that the sequence $\left(\nabla u_{n}\right)_{n}$ is Cauchy in measure.

Indeed, let $s>0$, and consider

$$
E_{1}:=\left\{\left|\nabla u_{n}\right|>h\right\} \cup\left\{\left|\nabla u_{m}\right|>h\right\}, \quad E_{2}:=\left\{\left|u_{n}-u_{m}\right|>k\right\}
$$

and

$$
E_{3}:=\left\{\left|\nabla u_{n}\right| \leq h,\left|\nabla u_{m}\right| \leq h,\left|u_{n}-u_{m}\right| \leq k,\left|\nabla u_{n}-\nabla u_{m}\right|>s\right\},
$$

where $\mathrm{h}$ and $\mathrm{k}$ will be chosen later.

Note that

$$
\left\{\left|\nabla u_{n}-\nabla u_{m}\right|>s\right\} \subset E_{1} \cup E_{2} \cup E_{3} .
$$

Let $\epsilon>0$. By Proposition 5.7 (relation (5.8)), we may choose $h=h(\epsilon)$ large enough such that

$$
\operatorname{meas}\left(E_{1}\right) \leq \epsilon / 3
$$


for all $n, m \geq 0$.

On the other hand, by Proposition 5.9

$$
\operatorname{meas}\left(E_{2}\right) \leq \epsilon / 3
$$

for all $n, m \geq n_{0}(k, \epsilon)$.

Moreover, since $a(x, \xi)$ is continuous with respect to $\xi$ for a.e every $x \in \Omega$, by assumption (2.5) there exists a real valued function $\gamma: \Omega \longrightarrow[0,+\infty]$ such that meas $(\{x \in \Omega: \gamma(x)=0\})=0$ and

$$
\left(a(x, \xi)-a\left(x, \xi^{\prime}\right)\right) \cdot\left(\xi-\xi^{\prime}\right) \geq \gamma(x)
$$

for all $\xi, \xi^{\prime} \in \mathbb{R}^{N}$ such that $|\xi| \leq h,\left|\xi^{\prime}\right| \leq h,\left|\xi-\xi^{\prime}\right| \geq s$, for a.e $x \in \Omega$.

Let $\delta=\delta(\epsilon)$ be given by Lemma 5.11., replacing $\epsilon$ and $A$ by $\epsilon / 3$ and $E_{3}$ respectively.

As $u_{n}$ is a weak solution of (5.22), using $T_{k}\left(u_{n}-u_{m}\right)$ as a test function, we get

$$
\begin{aligned}
\int_{\Omega} a\left(x, \nabla u_{n}\right) \cdot \nabla T_{k}\left(u_{n}-u_{m}\right) d x & +\int_{\Omega}\left|u_{n}\right|^{p(x)-2} u_{n} T_{k}\left(u_{n}-u_{m}\right) d x= \\
& \int_{\partial \Omega} \varphi_{n} T_{k}\left(u_{n}-u_{m}\right) d \sigma+\int_{\Omega} f_{n} T_{k}\left(u_{n}-u_{m}\right) d x \\
& \leq k\left(\|\varphi\|_{L^{1}(\partial \Omega)}+\|f\|_{L^{1}(\Omega)}\right) .
\end{aligned}
$$

Similarly for $\mathfrak{u}_{\mathrm{m}}$, we have

$$
\begin{aligned}
\int_{\Omega} a\left(x, \nabla u_{m}\right) \cdot \nabla T_{k}\left(u_{m}-u_{n}\right) d x & +\int_{\Omega}\left|u_{m}\right|^{p(x)-2} u_{m} T_{k}\left(u_{m}-u_{n}\right) d x= \\
& \int_{\partial \Omega} \varphi_{m} T_{k}\left(u_{m}-u_{n}\right) d \sigma+\int_{\Omega} f_{m} T_{k}\left(u_{m}-u_{n}\right) d x \\
& \leq k\left(\|\varphi\|_{L^{1}(\partial \Omega)}+\|f\|_{L^{1}(\Omega)}\right) .
\end{aligned}
$$

After adding the last two inequalities, it yields

$$
\left\{\begin{array}{l}
\int_{\left\{\left|u_{n}-u_{m}\right| \leq k\right\}}\left(a\left(x, \nabla u_{n}\right)-a\left(x, \nabla u_{m}\right)\right) \cdot\left(\nabla u_{n}-\nabla u_{m}\right) d x \\
+\int_{\Omega}\left(\left|u_{n}\right|^{p(x)-2} u_{n}-\left|u_{m}\right|^{p(x)-2} u_{m}\right) T_{k}\left(u_{n}-u_{m}\right) d x \leq 2 k\left(\|\varphi\|_{L^{1}(\partial \Omega)}+\|f\|_{L^{1}(\Omega)}\right) .
\end{array}\right.
$$

Since the second term of the above inequality is nonnegative, we obtain by using (5.38)

$$
\int_{E_{3}} \gamma(x) d x \leq \int_{E_{3}}\left(a\left(x, \nabla u_{n}\right)-a\left(x, \nabla u_{m}\right)\right) \cdot\left(\nabla u_{n}-\nabla u_{m}\right) d x \leq 2 k\left(\|\varphi\|_{L^{1}(\partial \Omega)}+\|f\|_{L^{1}(\Omega)}\right)<\delta
$$

where $k=\delta / 4\left(\|\varphi\|_{\mathrm{L}^{1}(\partial \Omega)}+\|f\|_{\mathrm{L}^{1}(\Omega)}\right)$.

From Lemma 5.11, it follows that

$$
\operatorname{meas}\left(E_{3}\right) \leq \epsilon / 3
$$


Thus using (5.35), (5.36), (5.37) and (5.39), we get

$$
\operatorname{meas}\left(\left\{\left|\nabla u_{n}-\nabla u_{m}\right|>s\right\}\right) \leq \epsilon, \text { for all } n, m \geq n_{0}(s, \epsilon)
$$

and then the claim is proved.

Consequently, $\left(\nabla u_{n}\right)_{n}$ converges in measure to some measurable function $v$. In order to end the proof of $(i)$, we need the following lemma:

\section{Lemma 5.13.}

(a) For a.e. $t \in \mathbb{R}, \nabla T_{t}\left(u_{n}\right)$ converges in measure to $v \chi_{\{|u|<t\}}$;

(b) for a.e. $\mathrm{t} \in \mathbb{R}, \nabla \mathrm{T}_{\mathrm{t}}(\mathrm{u})=v \chi_{\{|\mathrm{u}|<\mathrm{t}\}}$;

(c) $\nabla \mathrm{T}_{\mathrm{t}}(\mathrm{u})=v \mathrm{X}_{\{|\mathfrak{u}|<\mathrm{t}\}}$ holds for all $\mathrm{t} \in \mathbb{R}$.

\section{Proof of Lemma 5.13.}

\section{- Proof of (a).}

We know that $\nabla u_{n} \rightarrow v$ in measure. Thus, $\chi_{\{|\mathbf{u}|<t\}} \nabla u_{n} \rightarrow \chi_{\{|\mathfrak{u}|<t\}} v$ in measure.

Now, let us show that $\left(\chi_{\left\{\left|u_{n}\right|<t\right\}}-\chi_{\{|\mathfrak{u}|<t\}}\right) \nabla u_{n} \rightarrow 0$ in measure. For that, it is sufficient to show that $\left(\chi_{\left\{\left|\mathbf{u}_{n}\right|<\mathrm{t}\right\}}-\chi_{\{|\mathbf{u}|<\mathrm{t}\}}\right) \rightarrow 0$ in measure. Now, for all $\delta>0$,

$$
\begin{aligned}
& \left\{\left|\chi_{\left\{\left|u_{n}\right|<t\right\}}-\chi_{\{|u|<t\}}\right|\left|\nabla u_{n}\right|>\delta\right\} \subset\left\{\left|\chi_{\left\{\left|u_{n}\right|<t\right\}}-x_{\{|u|<t\}}\right| \neq 0\right\} \\
& \subset\{|\mathfrak{u}|=\mathrm{t}\} \cup\left\{\mathrm{u}_{\mathrm{n}}<\mathrm{t}<\mathfrak{u}\right\} \cup\left\{\mathfrak{u}<\mathrm{t}<\mathrm{u}_{n}\right\} \cup\left\{\mathrm{u}_{\mathrm{n}}<-\mathrm{t}<\mathfrak{u}\right\} \cup\left\{\mathfrak{u}<-\mathrm{t}<\mathrm{u}_{n}\right\} .
\end{aligned}
$$

Thus,

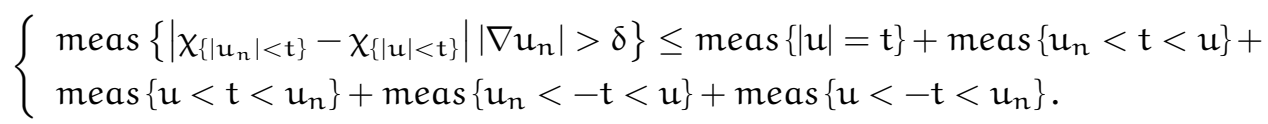

Note that

$\operatorname{meas}\{|\mathrm{u}|=\mathrm{t}\} \leq \operatorname{meas}\{\mathrm{t}-\mathrm{h}<\mathrm{u}<\mathrm{t}+\mathrm{h}\}+\operatorname{meas}\{-\mathrm{t}-\mathrm{h}<\mathrm{u}<-\mathrm{t}+\mathrm{h}\} \rightarrow 0$ as $\mathrm{h} \rightarrow 0$

for a.e. $t$, since $u$ is a fixed function. Next,

$$
\operatorname{meas}\left\{u_{n}<t<u\right\} \leq \operatorname{meas}\{t<u<t+h\}+\text { meas }\left\{\left|u-u_{n}\right|>h\right\} \text {, for all } h>0 \text {. }
$$

Due to Proposition 5.9, we have for all fixed $h>0$, meas $\left\{\left|u-u_{n}\right|>h\right\} \rightarrow 0$ as $n \rightarrow+\infty$. Since meas $\{t<u<t+h\} \rightarrow 0$ as $h \rightarrow 0$, for all $\epsilon>0$, one can find $N$ such that for all $n>N$, meas $\left\{u_{n}<t<u\right\}<\epsilon / 2+\epsilon / 2=\epsilon$ by choosing $h$ and then $N$. Each of the other terms in the right-hand side of (5.41) can be treated in the same way as for meas $\left\{u_{n}<t<u\right\}$. Thus, meas $\left\{\left|\chi_{\left\{\left|u_{n}\right|<t\right\}}-\chi_{\{|\mathbf{u}|<\mathrm{t}\}}\right|\left|\nabla u_{n}\right|>\delta\right\} \rightarrow 0$ as $n \rightarrow+\infty$.

Finally, since $\nabla \mathrm{T}_{\mathrm{t}}\left(\mathrm{u}_{\mathrm{n}}\right)=\nabla \mathrm{u}_{n} \boldsymbol{\chi}_{\left\{\left|\mathbf{u}_{n}\right|<\mathrm{t}\right\}}$, the claim (a) follows.

\section{- Proof of (b).}


Let $\psi_{t}$ be the weak $W^{1, p(\cdot)}$-limit of $T_{t}\left(u_{n}\right)$, then it is also the strong $L^{1}$-limit of $T_{t}\left(u_{n}\right)$. But, as $T_{t}$ is a Lipschitz function, the convergence in measure of $u_{n}$ to $u$ implies the convergence in measure of $T_{t}\left(u_{n}\right)$ to $T_{t}(u)$. Thus, by the uniqueness of the limit in measure, $\psi_{t}$ is identified with $T_{t}(u)$, we conclude that $\nabla \mathrm{T}_{\mathfrak{t}}\left(\mathrm{u}_{\mathfrak{n}}\right) \rightarrow \nabla \mathrm{T}_{\mathrm{t}}(\mathrm{u})$ weakly in $\mathrm{L}^{\mathrm{p}(\cdot)}(\Omega)$.

The previous convergence also ensures that $\nabla \mathrm{T}_{\mathrm{t}}\left(\mathrm{u}_{\mathfrak{n}}\right)$ converges to $\nabla \mathrm{T}_{\mathrm{t}}(\mathrm{u})$ weakly in $\mathrm{L}^{1}(\Omega)$. On the other hand, by (a), $\nabla \mathrm{T}_{\mathbf{t}}\left(\mathrm{u}_{n}\right)$ converges to $v \chi_{\{|\mathfrak{u}|<\mathrm{t}\}}$ in measure. By lemma 5.10, since $\nabla \mathrm{T}_{\mathrm{t}}\left(\mathrm{u}_{\mathrm{n}}\right)$ is uniformly bounded in $L^{p_{-}}(\Omega)$, the convergence is actually strong in $L^{1}(\Omega)$; thus it is also weak in $L^{1}(\Omega)$. By the uniqueness of a weak $L^{1}$-limit, $v \chi_{\{|\mathfrak{u}|<t\}}$ coincides with $\nabla T_{t}(\mathfrak{u})$.

- Proof of (c)

Let $0<\mathrm{t}<\mathrm{s}$, and $\mathrm{s}$ be such that $v \chi_{\{|\mathfrak{u}|<s\}}$ coincides with $\nabla \mathrm{T}_{\mathrm{s}}(\mathrm{u})$. Then

$$
\nabla \mathrm{T}_{\mathrm{t}}(\mathrm{u})=\nabla \mathrm{T}_{\mathrm{t}}\left(\mathrm{T}_{\mathrm{s}}(\mathrm{u})\right)=\nabla \mathrm{T}_{\mathrm{s}}(\mathrm{u}) \mathrm{X}_{\left\{\left|\mathrm{T}_{\mathrm{s}}(\mathrm{u})\right|<\mathrm{t}\right\}}=v \mathrm{X}_{\{|\mathrm{u}|<s\}} \mathrm{X}_{\{|\mathrm{u}|<\mathrm{t}\}}=v \chi_{\{|\mathrm{u}|<\mathrm{t}\}} .
$$

Now, we can end the proof of (i). Indeed, combining Lemma 5.13-(c) and Proposition 5.1, (i) follows.

(ii) Let $s>0, k>0$ and consider

$$
\begin{gathered}
\mathrm{E}_{4}=\left\{\left|\nabla \mathrm{u}_{n}-\nabla \mathrm{u}_{\mathrm{m}}\right|>\mathrm{s},\left|\mathrm{u}_{\mathrm{n}}\right| \leq \mathrm{k},\left|\mathrm{u}_{\mathrm{m}}\right| \leq \mathrm{k}\right\}, \mathrm{E}_{5}=\left\{\left|\nabla \mathrm{u}_{\mathrm{m}}\right|>\mathrm{s},\left|\mathrm{u}_{\mathrm{n}}\right|>\mathrm{k},\left|\mathrm{u}_{\mathrm{m}}\right| \leq \mathrm{k}\right\}, \\
\mathrm{E}_{6}=\left\{\left|\nabla \mathrm{u}_{\mathrm{n}}\right|>\mathrm{s},\left|\mathrm{u}_{\mathrm{m}}\right|>\mathrm{k},\left|\mathrm{u}_{\mathrm{n}}\right| \leq \mathrm{k}\right\} \text { and } \mathrm{E}_{7}=\left\{0>\mathrm{s},\left|\mathrm{u}_{\mathrm{m}}\right|>\mathrm{k},\left|\mathrm{u}_{\mathrm{n}}\right|>\mathrm{k}\right\} .
\end{gathered}
$$

Note that

$$
\left\{\left|\nabla \mathrm{T}_{k}\left(\mathrm{u}_{\mathrm{n}}\right)-\nabla \mathrm{T}_{\mathrm{k}}\left(\mathrm{u}_{\mathrm{m}}\right)\right|>s\right\} \subset \mathrm{E}_{4} \cup \mathrm{E}_{5} \cup \mathrm{E}_{6} \cup \mathrm{E}_{7} .
$$

Let $\epsilon>0$. By Proposition 5.7, we may choose $k(\epsilon)$ such that

$$
\operatorname{meas}\left(E_{5}\right) \leq \frac{\epsilon}{4}, \operatorname{meas}\left(E_{6}\right) \leq \frac{\epsilon}{4} \text { and } \operatorname{meas}\left(E_{7}\right) \leq \frac{\epsilon}{4} .
$$

Therefore, using (5.40), (5.42) and (5.43), we get

$$
\operatorname{meas}\left(\left\{\left|\nabla \mathrm{T}_{k}\left(\mathrm{u}_{\mathrm{n}}\right)-\nabla \mathrm{T}_{\mathrm{k}}\left(\mathrm{u}_{\mathrm{m}}\right)\right|>\mathrm{s}\right\}\right) \leq \epsilon, \text { for all } \mathrm{n}, \mathrm{m} \geq \mathrm{n}_{1}(\mathrm{~s}, \epsilon) .
$$

Consequently, $\nabla \mathrm{T}_{k}\left(\mathrm{u}_{\mathrm{n}}\right)$ converges in measure to $\nabla \mathrm{T}_{k}(\mathrm{u})$.

Then, using lemmas 5.8 and 5.10, (ii) follows.

(iii) By lemmas 5.10 and 5.13, we have that for all $\mathrm{t}>0, \mathrm{a}\left(\mathrm{x}, \nabla \mathrm{T}_{\mathrm{t}}\left(\mathrm{u}_{\mathrm{n}}\right)\right)$ converges to $\mathrm{a}\left(\mathrm{x}, \nabla \mathrm{T}_{\mathrm{t}}(\mathrm{u})\right)$ in $\left(\mathrm{L}^{1}(\Omega)\right)^{\mathrm{N}}$ strongly and $\mathrm{a}\left(\mathrm{x}, \nabla \mathrm{T}_{\mathrm{t}}\left(\mathrm{u}_{\mathrm{n}}\right)\right)$ converges to $\chi_{\mathrm{t}} \in\left(\mathrm{L}^{\mathfrak{p}^{\prime}(.)}(\Omega)\right)^{\mathrm{N}}$ in $\left(\mathrm{L}^{\mathrm{p}^{\prime}(.)}(\Omega)\right)^{\mathrm{N}}$ weakly. Since each of the convergences implies the weak $L^{1}$-convergence, $\chi_{t}$ can be identified with $a\left(x, \nabla T_{t}(u)\right)$; thus, $\mathrm{a}\left(x, \nabla \mathrm{T}_{\mathrm{t}}(\mathrm{u})\right) \in\left(\mathrm{L}^{\mathrm{p}^{\prime}(.)}(\Omega)\right)^{\mathrm{N}}$. The proof of (iii) is then complete.

(iv) As $u_{n}$ is a weak solution of (5.22), using $T_{k}\left(u_{n}\right)$ as a test function, we get

$$
\int_{\Omega}\left|T_{k}\left(u_{n}\right)\right|^{p(x)} d x \leq \int_{\Omega}\left|u_{n}\right|^{p(x)-2} u_{n} T_{k}\left(u_{n}\right) d x \leq k\left(\|\varphi\|_{L^{1}(\partial \Omega)}+\|f\|_{L^{1}(\Omega)}\right) .
$$


We deduce from (5.24) and (5.45) that

$$
\int_{\Omega}\left|\mathrm{T}_{k}\left(u_{n}\right)\right|^{p_{-}} \mathrm{d} x \leq k\left(\|\varphi\|_{L^{1}(\partial \Omega)}+\|f\|_{L^{1}(\Omega)}\right)+\operatorname{meas}(\Omega),
$$

and

$$
\int_{\Omega}\left|\nabla \mathrm{T}_{\mathrm{k}}\left(\mathrm{u}_{\mathrm{n}}\right)\right|^{\mathrm{p}_{-}} \mathrm{d} x \leq \mathrm{k}\left(\|\varphi\|_{\mathrm{L}^{1}(\partial \Omega)}+\|\mathrm{f}\|_{\mathrm{L}^{1}(\Omega)}\right)+\operatorname{meas}(\Omega) .
$$

Furthermore, $T_{k}\left(u_{n}\right)$ converges weakly to $T_{k}(u)$ in $W^{1, p_{-}}(\Omega)$ and since for every $1 \leq p \leq+\infty$,

$$
\tau: W^{1, p}(\Omega) \rightarrow L^{p}(\partial \Omega), u \mapsto \tau(u)=\left.u\right|_{\partial \Omega}
$$

is compact, we deduce that $T_{k}\left(u_{n}\right)$ converges strongly to $T_{k}(u)$ in $L^{p-}(\partial \Omega)$ and so, up to a subsequence, we can assume that $T_{k}\left(u_{n}\right)$ converges to $T_{k}(u)$, a.e. on $\partial \Omega$. In other words, there exists $C \subset \partial \Omega$ such that $T_{k}\left(u_{n}\right)$ converges to $T_{k}(u)$ on $\partial \Omega \backslash C$ with $\mu(C)=0$ where $\mu$ is the area measure on $\partial \Omega$.

Now, we use Hölder Inequality, (5.46) and (5.47) to get

$$
\int_{\Omega}\left|\mathrm{T}_{k}\left(u_{n}\right)\right| \mathrm{d} x \leq(\operatorname{meas}(\Omega))^{\frac{1}{(\mathfrak{p}-)^{\prime}}}\left(\mathrm{k}\left(\|\varphi\|_{\mathrm{L}^{1}(\partial \Omega)}+\|f\|_{\mathrm{L}^{1}(\Omega)}\right)+\operatorname{meas}(\Omega)\right)^{\frac{1}{\mathrm{p}-}},
$$

and

$$
\int_{\Omega}\left|\nabla \mathrm{T}_{\mathrm{k}}\left(\mathrm{u}_{\mathrm{n}}\right)\right| \mathrm{d} x \leq(\operatorname{meas}(\Omega))^{\frac{1}{(\mathfrak{p}-)^{\prime}}}\left(\mathrm{k}\left(\|\varphi\|_{\mathrm{L}^{1}(\partial \Omega)}+\|\mathrm{f}\|_{\mathrm{L}^{1}(\Omega)}\right)+\operatorname{meas}(\Omega)\right)^{\frac{1}{\mathrm{p}_{-}}} .
$$

By using Fatou's Lemma in (5.48) and (5.49) we get as $n$ goes to $+\infty$,

$$
\int_{\Omega}\left|\mathrm{T}_{\mathrm{k}}(\mathrm{u})\right| \mathrm{dx} \leq(\operatorname{meas}(\Omega))^{\frac{1}{\left(\mathfrak{p}_{-}\right)}}\left(\mathrm{k}\left(\|\varphi\|_{\mathrm{L}^{1}(\partial \Omega)}+\|\mathrm{f}\|_{\mathrm{L}^{1}(\Omega)}\right)+\operatorname{meas}(\Omega)\right)^{\frac{1}{p_{-}}},
$$

and

$$
\int_{\Omega}\left|\nabla \mathrm{T}_{\mathrm{k}}(\mathrm{u})\right| \mathrm{d} x \leq(\operatorname{meas}(\Omega))^{\frac{1}{\left(\mathrm{p}_{-}\right)^{\prime}}}\left(\mathrm{k}\left(\|\varphi\|_{\mathrm{L}^{1}(\partial \Omega)}+\|\mathrm{f}\|_{\mathrm{L}^{1}(\Omega)}\right)+\operatorname{meas}(\Omega)\right)^{\frac{1}{\mathrm{p}_{-}}} .
$$

For every $k>0$, let $A_{k}:=\left\{x \in \partial \Omega:\left|T_{k}(u(x))\right|<k\right\}$ and $C^{\prime}=\partial \Omega \backslash \bigcup_{k>0} A_{k}$.

We have

$$
\begin{aligned}
\mu\left(\mathrm{C}^{\prime}\right)=\frac{1}{\mathrm{k}} \int_{\mathrm{C}^{\prime}}\left|\mathrm{T}_{\mathrm{k}}(\mathrm{u})\right| \mathrm{d} x & \leq \frac{1}{\mathrm{k}} \int_{\partial \Omega}\left|\mathrm{T}_{\mathrm{k}}(\mathrm{u})\right| \mathrm{d} x \\
& \leq \frac{\mathrm{C}_{1}}{\mathrm{k}}\left\|\mathrm{T}_{\mathrm{k}}(\mathrm{u})\right\|_{\mathrm{W}^{1}, 1(\Omega)} \\
& \leq \frac{\mathrm{C}_{1}}{\mathrm{k}}\left\|\mathrm{T}_{\mathrm{k}}(\mathrm{u})\right\|_{\mathrm{L}^{1}(\Omega)}+\frac{\mathrm{C}_{1}}{\mathrm{k}}\left\|\nabla \mathrm{T}_{\mathrm{k}}(\mathrm{u})\right\|_{\mathrm{L}^{1}(\Omega)} .
\end{aligned}
$$

According to (5.50) and (5.51), we deduce by letting $k \rightarrow+\infty$ that $\mu\left(C^{\prime}\right)=0$.

Let us define in $\partial \Omega$ the function $v$ by

$$
v(x):=T_{k}(u(x)) \text { if } x \in A_{k} .
$$


We take $x \in \partial \Omega \backslash\left(C \cup C^{\prime}\right)$; then there exists $k>0$ such that $x \in A_{k}$ and we have

$$
u_{n}(x)-v(x)=\left(u_{n}(x)-T_{k}\left(u_{n}(x)\right)\right)+\left(T_{k}\left(u_{n}(x)\right)-T_{k}(u(x))\right)
$$

Since $x \in A_{k}$, we have $\left|T_{k}(u(x))\right|<k$ and so $\left|T_{k}\left(u_{n}(x)\right)\right|<k$, from which we deduce that $\left|u_{n}(x)\right|<$ k.

Therefore

$$
u_{n}(x)-v(x)=\left(T_{k}\left(u_{n}(x)\right)-T_{k}(u(x))\right) \rightarrow 0, \text { as } n \rightarrow+\infty \text {. }
$$

This means that $u_{n}$ converges to $v$ a.e. on $\partial \Omega$.

The proof of the Proposition 5.12 is then complete.

We are now able to pass to the limit in the identity (5.34).

For the right-hand side, the convergence is obvious since $f_{n}$ converges strongly to $f$ in $L^{1}(\Omega)$, $\varphi_{n}$ converges strongly to $\varphi$ in $L^{1}(\partial \Omega)$ and $T_{k}\left(u_{n}-v\right)$ converges weakly-* to $T_{k}(u-v)$ in $L^{\infty}(\Omega)$ and a.e in $\Omega$ and to $T_{k}(u-v)$ in $L^{\infty}(\partial \Omega)$ and a.e in $\partial \Omega$.

For the second term of (5.34), we have

$$
\begin{aligned}
\int_{\Omega}\left|u_{n}\right|^{p(x)-2} u_{n} T_{k}\left(u_{n}-v\right) d x & =\int_{\Omega}\left(\left|u_{n}\right|^{p(x)-2} u_{n}-|v|^{p(x)-2} v\right) T_{k}\left(u_{n}-v\right) d x \\
& +\int_{\Omega}|v|^{p(x)-2} v T_{k}\left(u_{n}-v\right) d x .
\end{aligned}
$$

The quantity $\left(\left|u_{n}\right|^{p(x)-2} u_{n}-\mid v^{p(x)-2} v\right) T_{k}\left(u_{n}-v\right)$ is nonnegative and since for all $x \in \Omega, s \longmapsto|s|^{p(x)-2} s$ is continuous, we get

$$
\left(\left|u_{n}\right|^{p(x)-2} u_{n}-|v|^{p(x)-2} v\right) T_{k}\left(u_{n}-v\right) \longrightarrow\left(|u|^{p(x)-2} u-|v|^{p(x)-2} v\right) T_{k}(u-v) d x \text { a.e in } \Omega .
$$

Then, it follows by Fatou's Lemma that

$\liminf _{n \rightarrow+\infty} \int_{\Omega}\left(\left|u_{n}\right|^{p(x)-2} u_{n}-|v|^{p(x)-2} v\right) T_{k}\left(u_{n}-v\right) d x \geq \int_{\Omega}\left(|u|^{p(x)-2} u-|v|^{p(x)-2} v\right) T_{k}(u-v) d x$

Let us show that $|v|^{p(x)-2} v \in \mathrm{L}^{1}(\Omega)$.

We have

$$
\left.\left.\int_{\Omega}|| v\right|^{p(x)-2} v\left|\mathrm{~d} x=\int_{\Omega}\right| v\right|^{p(x)-1} \mathrm{~d} x \leq \int_{\Omega}\left(\|v\|_{\infty}\right)^{p(x)-1} \mathrm{~d} x .
$$

If $\|v\|_{\infty} \leq 1$, then $\left.\int_{\Omega}|| v\right|^{p(x)-2} v \mid \mathrm{d} x \leq \operatorname{meas}(\Omega)<+\infty$.

If $\|v\|_{\infty}>1$, then $\left.\int_{\Omega}|| v\right|^{p(x)-2} v \mid \mathrm{d} x \leq \int_{\Omega}\left(\|v\|_{\infty}\right)^{p_{+}-1} \mathrm{~d} x=\left(\|v\|_{\infty}\right)^{p_{+}-1} \operatorname{meas}(\Omega)<+\infty$. 
Hence $|v|^{p(x)-2} v \in \mathrm{L}^{1}(\Omega)$.

Since $T_{k}\left(u_{n}-v\right)$ converges weakly-* to $T_{k}(u-v)$ in $L^{\infty}(\Omega)$ and $|v|^{p(x)-2} v \in L^{1}(\Omega)$, it follows that

$$
\lim _{n \rightarrow+\infty} \int_{\Omega}|v|^{p(x)-2} v T_{k}\left(u_{n}-v\right) d x=\int_{\Omega}|v|^{p(x)-2} v T_{k}(u-v) d x .
$$

Next, we write the first term in (5.34) in the following form

$$
\int_{\left\{\left|u_{n}-v\right| \leq k\right\}} a\left(x, \nabla u_{n}\right) \cdot \nabla u_{n} d x-\int_{\left\{\left|u_{n}-v\right| \leq k\right\}} a\left(x, \nabla u_{n}\right) . \nabla v d x .
$$

Set $l=k+\|v\|_{\infty}$, the second integral in (5.52) equals to

$$
\int_{\left\{\left|u_{n}-v\right| \leq k\right\}} a\left(x, \nabla T_{l}\left(u_{n}\right)\right) . \nabla v d x .
$$

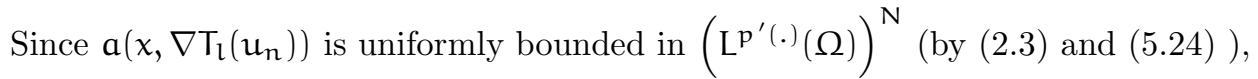

by Proposition $5.12-(\mathfrak{i i i})$, it converges weakly to $\mathrm{a}\left(x, \nabla \mathrm{T}_{\mathfrak{l}}(\mathrm{u})\right)$ in $\left(\mathrm{L}^{\mathrm{p}^{\prime}(\cdot)}(\Omega)\right)^{\mathrm{N}}$.

Therefore

$$
\lim _{n \rightarrow+\infty} \int_{\left\{\left|u_{n}-v\right| \leq k\right\}} a\left(x, \nabla T_{l}\left(u_{n}\right)\right) . \nabla v d x=\int_{\{|u-v| \leq k\}} a\left(x, \nabla T_{l}(u)\right) . \nabla v d x .
$$

Moreover $\mathrm{a}\left(\mathrm{x}, \nabla \mathrm{u}_{\mathrm{n}}\right) . \nabla \mathrm{u}_{\mathrm{n}}$ is nonnegative and converges a.e in $\Omega$ to $\mathrm{a}(\mathrm{x}, \nabla \mathrm{u}) . \nabla \mathrm{u}$.

Thanks to Fatou's Lemma, we obtain

$$
\liminf _{n \rightarrow+\infty} \int_{\left\{\left|u_{n}-v\right| \leq k\right\}} a\left(x, \nabla u_{n}\right) \cdot \nabla u_{n} d x \geq \int_{\{|u-v| \leq k\}} a(x, \nabla u) \cdot \nabla u d x .
$$

Gathering results, we obtain

$$
\int_{\Omega} a(x, \nabla u) \cdot \nabla T_{k}(u-v) d x+\int_{\Omega}|u|^{p(x)-2} u T_{k}(u-v) d x \leq \int_{\partial \Omega} \varphi T_{k}(u-v) d \sigma+\int_{\Omega} f T_{k}(u-v) d x .
$$

We conclude that $u$ is an entropy solution of (1.1).

\section{Acknowledgment}

The author want to express is deepest thanks to the editor and anonymous referee's for comments on the paper.

Received: January 2011. Revised: September 2011.

\section{References}

[1] A. Alvino, L. Boccardo, V. Ferone, L. Orsina \& G. Trombetti; Existence results for non-linear elliptic equations with degenerate coercivity, Ann. Mat. Pura Appl. 182 (2003), 53-79. 
[2] F. Andreu, N. Igbida, J.M. Mazón \& J. Toledo; L ${ }^{1}$ existence and uniqueness results for quasilinear elliptic equations with nonlinear boundary conditions, Ann. I.H. Poincaré AN., 24 (2007), $61-89$.

[3] F. Andreu, J. M. Mazón, S. Segura De Léon \& J. Toledo; Quasi-linear elliptic and parabolic equations in $\mathrm{L}^{1}$ with nonlinear boundary conditions, Adv. Math. Sci. Appl. 7 , no.1 (1997), 183-213.

[4] S.N. Antontsev \& J.F. Rodrigues; On stationary thermo-rheological viscous flows. Annal del Univ de Ferrara 52 (2006), 19-36.

[5] P. Bénilan, L. Boccardo, T. Gallouèt, R. Gariepy, M. Pierre, J.L. Vazquez, An L ${ }^{1}$ theory of existence and uniqueness of nonlinear elliptic equations, Ann Scuola Norm. Sup. Pisa, 22 no.2 (1995), 240-273.

[6] H. Brezis: Analyse Fonctionnelle: Théorie et Applications, Paris, Masson (1983).

[7] Y. Chen, S. Levine \& M. Rao; Variable exponent, linear growth functionals in image restoration. SIAM. J.Appl. Math., 66 (2006), 1383-1406.

[8] L. Diening; Riesz potential and Sobolev embeddings on generalized Lebesgue and Sobolev spaces $\mathrm{L}^{\mathrm{p}(.)}$ and $\mathrm{W}^{1, \mathrm{p}(.)}$, Math. Nachr. 268 (2004), 31-43.

[9] L. Diening; Theoretical and numerical results for electrorheological fluids, Ph.D. thesis, University of Freiburg, Germany, 2002.

[10] D. E. Edmunds \& J. Rakosnik; Density of smooth functions in $W^{k, p(x)}(\Omega)$, Proc. R. Soc. A 437 (1992), 229-236.

[11] D. E. Edmunds \& J. Rakosnik; Sobolev embeddings with variable exponent, Sudia Math. 143 (2000), 267-293.

[12] D. E. Edmunds \& J. Rakosnik; Sobolev embeddings with variable exponent, II, Math. Nachr. 246-247 (2002), 53-67.

[13] X. Fan \& S. Deng; Multiplicity of Positive Solutions for a Class of Inhomogeneous Neumann Problems Involving the $\mathrm{p}(\mathrm{x})$-Laplacian, Nonlinear differ.equ.appl. 16 (2009), 255-271.

[14] X. Fan \& Q. Zhang; Existence of solutions for $\mathrm{p}(\mathrm{x})$-Laplacian Dirichlet problem, Nonlinear Anal. 52 (2003), 1843-1852.

[15] X. Fan \& D. Zhao; On the spaces $\mathrm{L}^{\mathfrak{p}(\mathrm{x})}(\Omega)$ and $\mathrm{W}^{\mathrm{m}, \mathrm{p}(\mathrm{x})}(\Omega)$, J. Math. Anal. Appl. 263 (2001), 424-446.

[16] P. Halmos: Measure Theory, D. Van Nostrand, New York (1950).

[17] O. Kovacik \& J. Rakosnik; On spaces $\mathrm{L}^{\mathrm{p}(\mathrm{x})}$ and $\mathrm{W}^{1, \mathfrak{p}(\mathrm{x})}$, Czech. Math. J. 41 (1991), 592-618. 
[18] M. Krasnosel'skii; Topological methods in the theory of nonlinear integral equations, Pergamon Press, New York, 1964.

[19] M. Mihailescu \& V. Radulescu; A multiplicity result for a nonlinear degenerate problem arising in the theory of electrorheological fluids, Proc. R. Soc. A 462 (2006), 2625-2641.

[20] C. B. Jr. Morrey; Multiple Intégrals in the Calculus of Variations, Springer-Verlag, 1966.

[21] J. Musielak; Orlicz Spaces and modular spaces. Lecture Notes in Mathematics, vol. 1034 (1983), springer, Berlin.

[22] H. Nakano; Modulared semi-ordered linear spaces. Maruzen Co., Ltd., Tokyo, 1950.

[23] J. Necas; Les méthodes Directes en Théorie des Equations Elliptiques, Masson et Cie, Paris, 1967.

[24] S. Ouaro \& S. Soma; Weak and entropy solutions to nonlinear Neumann boundary value problem with variable exponent. Complex var. Elliptic Equ, 56, No. 7-9, 829-851 (2011).

[25] S. Ouaro \& S. Traoré; Existence and uniqueness of entropy solutions to nonlinear elliptic problems with variable growth. Int. J. Evol. Equ. 4 (2010), no. 4, 451-471.

[26] S. Ouaro \& S. Traoré; Weak and entropy solutions to nonlinear elliptic problems with variable exponent. J. Convex Anal. 16 , No. 2 (2009), 523-541.

[27] K.R. Rajagopal \& M. Ruzicka; Mathematical Modeling of Electrorheological Materials, Contin. Mech. Thermodyn. 13 (2001), 59-78.

[28] B. Ricceri; On three critical points theorem, Arch. Math. (Basel)75 (2000), 220-226.

[29] M. Ruzicka; Electrorheological fluids: modelling and mathematical theory, Lecture Notes in Mathematics 1748, Springer-Verlag, Berlin, 2002.

[30] M. Sanchon \& J. M. Urbano; Entropy solutions for the $\mathrm{p}(\mathrm{x})$-Laplace Equation, Trans. Amer. Math. Soc. 361 (2009), no. 12, 6387-6405.

[31] I. Sharapudinov; On the topology of the space $\mathrm{L}^{\mathrm{p}(\mathrm{t})}([0,1])$, Math. Zametki 26 (1978), 613-632.

[32] I. Tsenov; Generalization of the problem of best approximation of a function in the space $\mathrm{L}^{\mathrm{s}}$, Uch. Zap. Dagestan Gos. Univ. 7 (1961), 25-37.

[33] L. Wang, Y. Fan \& W. Ge; Existence and multiplicity of solutions for a Neumann problem involving the $\mathrm{p}(\mathrm{x})$ - Laplace operator. Nonlinear Anal. 71 (2009), 4259-4270.

[34] J. Yao; Solutions for Neumann boundary value problems involving $\mathrm{p}(\mathrm{x})$-Laplace operators, Nonlinear Anal. 68 (2008), 1271-1283.

[35] V. Zhikov; On passing to the limit in nonlinear variational problem. Math. Sb. 183 (1992), 47-84. 